RUNNING HEAD: STRUCTURE OF NARCISSISM

\title{
EXPLORING THE STRUCTURE OF NARCISSISM: TOWARDS AN INTEGRATED SOLUTION
}

\author{
Michael L. Crowe \\ University of Georgia \\ Donald R. Lynam \\ Purdue University \\ W. Keith Campbell \\ University of Georgia \\ Joshua D. Miller \\ University of Georgia
}

Correspondence concerning this article should be addressed to Michael L. Crowe, Department of Psychology, University of Georgia, Athens, GA 30602. Email: crowem@uga.edu. 
STRUCTURE OF NARCISSISM

\begin{abstract}
Objective: Despite decades of work on narcissism there remain many active areas of exploration and debate including a clear and consensual description of its underlying components. Understanding narcissism's factor structure is necessary for precise measurement and investigation of specific psychological and behavioral processes. The aim of the current study was to explore the structure of narcissism by examining it at varying hierarchical levels. Method: Participants recruited from Amazon's Mechanical Turk $(\mathrm{N}=591)$ completed 303 narcissism items encompassing 46 narcissism scales and subscales. Criterion variables measuring the Five Factor Model, self-esteem, aggression, and externalizing behavior were also collected. Results: A series of factor analyses reveal the factor structure of narcissism at a range of specificities. No more than five meaningful factors (i.e., Grandiosity, Neuroticism, Antagonism, Distrustful Self-reliance, Attention-seeking) were identified and the most parsimonious model appears to be a three-factor structure. Narcissism scales that effectively capture each of the identified factors are identified. Factors diverged in their associations with criterion variables. Conclusions: A three-factor model (i.e., Agentic Extraversion, Narcissistic Neuroticism, Self-centered Antagonism) seems to be the most parsimonious conceptualization. Larger factor solutions are discussed, but future research will be necessary to determine the value of these increasingly narrow factors.
\end{abstract}

INDEX WORDS: Bass-ackwards, factor analysis, narcissism, trifurcated model 
STRUCTURE OF NARCISSISM

EXPLORING THE STRUCTURE OF NARCISSISM: TOWARDS AN INTEGRATED SOLUTION

Narcissism refers to a collection of personality traits. However, despite a century of scientific inquiry, a consensual definition of the construct (i.e., exactly which traits should be included within the structure) is still lacking (Krizan \& Herlache, 2018; Miller, Lynam, Hyatt, \& Campbell, 2017; Miller, Lynam, Siedor, Crowe, \& Campbell, 2018; Wright \& Edershile, 2018). This lack of a clear operational definition for the construct has impaired progress and led to conflicting accounts of narcissism's empirical profile, some indicating an association with selfconfident exhibitionism and others indicating shyness and social withdrawal (see Wink, 1991 for discussion), for instance. In order for scientific inquiry to be cumulative, narcissism must have commonly accepted conceptual boundaries and measures. Some progress has been made on this front. In the past 20 years there has been broad recognition of the need to distinguish between grandiose and vulnerable expressions (Cain, Pincus, \& Ansell, 2008; Dickinson \& Pincus, 2003; Miller \& Campbell, 2008; Wink, 1991). When narcissism measures were reorganized to reflect that structure (i.e., understood as measures of grandiose or vulnerable narcissism) the conflicting empirical accounts began to be clarified and resolved (Miller, Hoffman, et al., 2011; Pincus et al., 2009). However, a fundamental problem remains. If grandiose and vulnerable narcissism are to be conceptualized as a common personality-based difficulty, if they are both narcissism, they must share some common aspects. An underlying structure that unites both grandiose and vulnerable narcissistic expressions should be present.

Narcissism has been described as a "paradox" because grandiose and vulnerable narcissism seem incongruent in many ways (Morf \& Rhodewalt, 2001). Grandiose narcissism is characterized, in part, by high self-esteem, sociability, assertiveness, and exhibitionism while 
STRUCTURE OF NARCISSISM

vulnerable narcissism typically includes low self-esteem, social withdrawal, and negative emotionality (Miller \& Campbell, 2008; Miller, Hoffman, et al., 2011; Wink, 1991). However, analyses have consistently shown that grandiose and vulnerable narcissistic expressions share interpersonally antagonistic traits such as entitlement, egotism, and non-compliance (Miller \& Campbell, 2008; Miller, Lynam, et al., 2017; Wink, 1991). A unifying structural model of narcissism would be capable of accounting for both the convergence and divergence of grandiose and vulnerable narcissism by incorporating both shared and unique traits. Such a model would resolve boundary and criterion problems by identifying the "core" of narcissism (i.e., those traits shared by all expressions) as well as the traits specific to individual expressions. As with the grandiose and vulnerable distinction, a unifying structural model would also allow for organization and understanding of narcissism measures, not only benefitting future analyses, but also clarifying previous studies. Previous attempts in pursuit of this goal have already been made.

\section{Structural Integration of Grandiose and Vulnerable Narcissism}

Many narcissism measures in active use include underlying structural models (Back et al., 2013; Foster, McCain, Hibberts, Brunell, \& Johnson, 2015; Glover, Miller, Lynam, Crego, \& Widiger, 2012; Pincus et al., 2009). In each case, unique theoretical perspectives resulted in somewhat unique structural models. Most recently, two three-factor models have been empirically derived, the trifurcated model (Miller, Lynam, et al., 2017; Miller, Lynam, McCain, et al., 2016) and the Narcissistic Spectrum Model (NSM; Krizan \& Herlache, 2018). Both were identified through factor analyses of narcissism scales, and both models argue for a three-factor conceptualization of narcissism's structure: Agentic Extraversion/Exhibitionism;

Antagonism/Entitlement; Neuroticism/Vulnerability. The models accommodate both grandiose 
STRUCTURE OF NARCISSISM

and vulnerable narcissism through recognition of a common antagonistic core (e.g., entitlement, arrogance, manipulativeness). The traits that are present in only grandiose (e.g., exhibitionism, authoritativeness) or vulnerable (e.g., shame, need for admiration) narcissism are then conceptualized as more peripheral components specific to particular presentations.

Although both the trifurcated model and narcissistic spectrum model are effective in their ability to resolve many previously identified measurement conflicts (Wright \& Edershile, 2018), the models have limitations that must be acknowledged. In both cases, sub-scale scores rather than individual items were submitted to factor analytic techniques. Although analysis of homogenous item parcels can simplify factor solutions, the approach can become problematic even when parcels are relatively homogeneous (Marsh, Lüdtke, Nagengast, Morin, \& Von Davier, 2013). It is possible that in previous analyses relevant traits, buried within item parcels, failed to emerge from the final structural models. Both approaches were also constrained by the use of a limited number of measures. In all factor analyses the validity of the factor solution is contingent on items that effectively cover the entirety of the target domain. This is particularly relevant when considering a construct with poorly defined boundaries like narcissism. Miller and colleagues (2016) were reliant on the FFNI, while the FFNI and PNI made up 21 of the 26 subscales in Krizan and Herlache's (2018) analyses. Neither the trifurcated model nor the narcissistic spectrum model included items from any of the DSM-based narcissism measures (e.g., PDQ-4; PID-5) or other popular measures such as the Narcissistic Admiration and Rivalry Questionnaire (NARQ; Back et al., 2013) or Hypersensitive Narcissism Scale (HSNS; Hendin \& Cheek, 1997). Incomplete coverage may have biased or constrained the resulting solutions. Lastly, both models describe the narcissism domain out to only three-factors (Krizan \& 
STRUCTURE OF NARCISSISM

Herlache, 2018; Miller, Lynam, McCain, et al., 2016) and it is possible that additional, core factors are necessary to fully describe narcissism.

The goal of the present study is to explore the structure of narcissism. The present analyses address previous limitations by maximizing both item coverage and model flexibility. Item content from most major measures and conceptualizations of the narcissism domain were included, which helps ensure that no trait relevant to the narcissism domain was excluded from the model and that the resulting factor solutions are not unduly biased by the content and implied conceptualization of any one scale. An item-level factor analytic approach also maximizes the flexibility of the resulting solutions and allow for identification of homogeneous narcissism factors well suited for investigating the psychological processes of unique narcissistic expressions (Smith, McCarthy, \& Zapolski, 2009).

\section{The "Bass-Ackward" Approach to Understanding the Narcissism Domain}

Goldberg (2006) described a methodology capable of constructing a "hierarchical" model of personality structure. Goldberg's (2006) "Bass-ackward” approach uses a series of factor analyses to describe the factor space of a construct in a step-wise fashion from a single factor, representing what is most common to the data, to as many factors as can be interpreted. In each progressive factor solution, the factor scores are saved so that the relations of factors from adjacent levels of analyses can be compared. This method allows researchers to develop a map of factor emergence from most-broad to most-narrow. By incorporating all items from each of the identified measures we can be reasonably confident that all traits relevant to the narcissism domain, as it is currently conceptualized within the literature, are represented. Rather than developing a new measure or basing the factor analysis on a few isolated conceptualizations of the construct, this a-theoretical approach defines narcissism as simply that which is being 
STRUCTURE OF NARCISSISM

measured by narcissism scales. The result is a hierarchical model of narcissism that is by definition consensual, in the sense that it is democratically composed of items from all narcissism measures in active use.

The flexibility of the potential factor solutions is maximized by using narcissism items rather than scales, subscales, or parcels. Furthermore, by utilizing an inclusive pool of over 200 items, the likely number of indicators for each factor is increased along with factor stability (Marsh et al., 2013; Schmitt, Sass, Chappelle, \& Thompson, 2018). The first factor is expected to be indicative of what is most common to the narcissism scales, a grandiose sense of selfimportance. At the two-factor level, grandiose and vulnerable narcissism constructs, consistent with those found in the literature, are expected to emerge. The three-factor solution is expected to replicate the three-factor models identified by both Miller and colleagues (2016) and Krizan and Herlache (2018). Factor solutions at the fourth level of analysis and beyond should be interpreted as more fully exploratory in nature.

The identified factors from varying levels of the hierarchy identified via the bassackwards approach are then correlated with several external criterion variables (i.e., Five Factor Model, externalizing behavior, aggression, self-esteem) to better characterize their nature. The number of narcissism items collected for this analysis necessarily limits the number of outcome variables that can reasonably be collected. These criterion variables were selected due to their coverage (e.g., Five Factor Model), known association with narcissism dimensions (e.g., selfesteem), and relations with antagonistic personality pathology (e.g., aggression, externalizing behavior). Narcissism is expected to have significant divergence at the three-factor level with the Agentic Extraversion/Exhibitionism factor showing positive associations with FFM Extraversion and self-esteem, the Neuroticism/Vulnerability factor showing a positive association with FFM 
STRUCTURE OF NARCISSISM

Neuroticism and a negative association with self-esteem, and the Antagonism/Entitlement factor showing a negative association with FFM Agreeableness and a positive association with antisocial behaviors.

\section{METHOD}

\section{Participants and Procedure}

The sample consisted of 707 adults recruited from Amazon's Mechanical Turk (MTurk) website. MTurk has been identified as a reliable source of data with more demographic diversity than most undergraduate populations (Chandler \& Shapiro, 2016; Miller, Crowe, Weiss, MaplesKeller, \& Lynam, 2017). Participants were required to be 18 years of age or older and to reside in the United States. Participants were excluded for invalid responding (see Validity Scales in Measures; $\mathrm{n}=86$ ), for finishing the study in a time deemed invalid (i.e., averaging less than two seconds per item; $\mathrm{n}=26$ ), and for invariant responding on the IPIP-NEO-120 (i.e., selecting a single response option for at least 90 of the 120 responses; $n=4)$. The final sample consisted of 591 individuals $\left(62 \%\right.$ women; $M_{\text {age }}=37.0$ years, $S D_{\text {age }}=11.8$ years; $79 \%$ white $)$. Some data from this sample were previously published (Crowe, Sleep, Carter, Campbell, \& Miller, 2018; Miller, Lynam, Siedor, et al., 2018; Miller, Lynam, Vize, et al., 2018; Vize et al., 2017)

\section{Measures}

\section{Narcissism item pool.}

Five Factor Narcissism Inventory Short Form (FFNI-SF). The FFNI-SF (Sherman et al., 2015) is a 60-item abbreviated form of the FFNI (Glover et al., 2012). The FFNI and FFNISF measure 15 facets that can be aggregated to form measures of grandiose $(\alpha=.94)$ and vulnerable $(\alpha=.85)$ narcissism as well as three empirically-derived higher-order factors (Miller, 
STRUCTURE OF NARCISSISM

Lynam, McCain, et al., 2016): Agentic Extraversion $(\alpha=.90)$, Antagonism $(\alpha=.92)$,

Neuroticism $(\alpha=.88)$.

Grandiose Narcissism Scale (GNS). The GNS (Foster et al., 2015) contains 33 items intended to measure the seven facet scales of grandiose narcissism originally proposed for the Narcissistic Personality Inventory (Raskin \& Terry, 1988). Subscale alpha reliabilities ranged from .75 (Self-sufficiency) to .93 (Authority).

Hypersensitive Narcissism Scale (HSNS). The HSNS (Hendin \& Cheek, 1997) is a 10item measure of narcissistic vulnerability, hypersensitivity, and entitlement ( $\alpha=.77)$.

Narcissistic Admiration and Rivalry Questionnaire (NARQ). The NARQ (Back et al., 2013) is an 18-item measure that was developed to assess a theoretical process model of narcissism labeled the Narcissistic Admiration and Rivalry Concept (NARC). The NARC model proposes two distinct, but related narcissistic social processes intended to maintain a grandiose self: Admiration (i.e., assertive self-enhancement; $\alpha=.84$ ) and Rivalry (i.e., antagonistic selfprotection; $\alpha=.80)$.

Narcissistic Grandiosity Scale (NGS). The NGS (Rosenthal et al., 2007) is a 16-item adjective-based measure of narcissistic grandiosity intended to measure a grandiose sense of selfimportance without overly confounding the construct with normative self-esteem $(\alpha=.93)$. A recent examination concluded that the NGS is a unidimensional measure of narcissistic grandiosity with strong convergent and discriminant validity (Crowe et al., 2016).

Narcissistic Personality Inventory (NPI). The NPI (Raskin \& Terry, 1988) is a 40-item forced-choice measure of narcissistic grandiosity; in the current study, the 40-item Likert version (see Miller, Gentile, et al., 2018) was used. Ackerman and colleagues (2011) three-factor 
STRUCTURE OF NARCISSISM

solution yielded the following alphas: Leadership/Authority (NPI LA; $\alpha=.90$ ), Grandiose

Exhibitionism (NPI GE; $\alpha=.82$ ), Entitlement/Exploitativeness (NPI EE; $\alpha=.68$ ).

Personality Diagnostic Questionnaire-4 Narcissistic Personality Disorder Scale (PDQ-

4+). The PDQ-4+ (Hyler, 1994) is a 99-item self-report measure of DSM-IV personality

disorders. The nine NPD items $(\alpha=.78)$ in the scale were developed to assess each of the nine NPD symptom criteria in the DSM-IV.

Psychological Entitlement Scale (PES). The PES (Campbell, Bonacci, Shelton, Exline, \& Bushman, 2004) is a nine-item inventory developed to measure psychological entitlement, conceptualized as a "stable and pervasive sense that one deserves more and is entitled to more than others" (p. $31 ; \alpha=.78)$.

Personality Inventory for the DSM-5 (PID-5) - NPD Scale. The PID-5 (Krueger et al., 2012) is a 220-item measure designed to assess the 25 personality traits included in Section III of the DSM-5. The PID-5 Attention Seeking $(\alpha=.91)$ and Grandiosity $(\alpha=.85)$ scales are averaged to create a DSM-5 NPD trait score $(\alpha=.91)$.

Pathological Narcissism Inventory (PNI). The PNI (Pincus et al., 2009) is a 52-item measure designed to measure "pathologically narcissistic" traits related to vulnerable and grandiose narcissism. Subscales of the PNI can be combined to assess vulnerable narcissism (i.e., Contingent Self-esteem, Hiding the Self, Devaluing, and Entitlement Rage; $\alpha=.94$ ) and grandiose narcissism (i.e., Self-sacrificing Self-enhancement, Grandiose Fantasies, and Exploitativeness; $\alpha=.88)$.

Short Dark Triad (SD3) - Narcissism Scale. The SD3 (Jones \& Paulhus, 2014) is a 27item measure of the "Dark Triad" (i.e., Machiavellianism, narcissism, psychopathy). Only the nine narcissism items from the scale were collected $(\alpha=.79)$. 
STRUCTURE OF NARCISSISM

Structured Clinical Interview for the DSM-IV Personality Disorders Personality

Questionnaire - NPD Scale (SCID-II NPD). The SCID-II (First et al., 1997) is a 119-item selfreport questionnaire derived from the DSM-IV structured clinical interview. The 17-item NPD items $(\alpha=.87)$ were included in these analyses.

\section{Criterion measures.}

International Personality Item Pool representation of the Revised NEO Personality Inventory - 120 item version (IPIP-NEO-120). The IPIP-NEO-120 (Maples, Guan, Carter, \& Miller, 2014) is a 120-item measure of the five domains and 30 facets of the five-factor model of personality. Facet level reliabilities ranged from $\alpha=.65$ (Morality) to $\alpha=.93$ (Depression). Domain level reliabilities ranged from $\alpha=.83$ (Openness) to .94 (Neuroticism).

Crime and Analogous Behavior scale (CAB). The CAB (Miller \& Lynam, 2003) assesses substance use, antisocial behavior, and intimate partner violence. The substance use variable was calculated by counting the number of five different substances participants endorsed trying. The antisocial behavior variable was calculated by counting the number of nine different behaviors endorsed. The intimate partner violence variable was calculated by counting the number of six different acts of violence toward a romantic partner that the participant endorsed.

Patient-reported Outcomes Measurement Information System (PROMIS) Anxiety and Depression Short Form Scales. The PROMIS Anxiety (PROMIS-A) and PROMIS Depression (PROMIS-D) short form inventories are seven and eight items respectively. For these analyses the PROMIS-A and PROMIS-D short form scales were combined to make a single 15 item measure of emotional distress $(\alpha=.97$; Pilkonis et al., 2011) 
STRUCTURE OF NARCISSISM

Reactive and Proactive Aggression Questionnaire (RPA). The RPA (Raine et al., 2006) consists of 23 self-report items assessing two forms of aggression: Proactive Aggression ( $\alpha=$ .82 ) and Reactive Aggression $(\alpha=.82$ ). Items are scored on a 0 (never) to 2 (often) scale.

Rosenberg Self-esteem Scale (RSES). The RSES (Rosenberg, 1965) is a 10-item global measure of self-esteem in which the items are scored on a 1 (Disagree strongly) to 4 (Agree strongly) scale $(\alpha=.92)$.

Validity Scales. Two validity scales from the Elemental Psychopathy Assessment (Lynam et al., 2011) were used - the Infrequency Scale (e.g., "I try to eat something almost every day"; reversed), and the Too Good to Be True Scale (e.g., "I have never in my life been angry at another person."). Participants' data were omitted if they received a score of four or more on the Infrequency Scale or a score of three or more on the Too Good to Be True Scale. The 16 items from these two scales were embedded within the pool of narcissism items.

\section{Data Analysis}

Before data collection occurred, all narcissism items from each scale were intermixed into a single pool of 303 items (i.e., 287 narcissism items and 16 validity scale items). Items not originally presented in the form of a complete sentence were put into sentence form for the sake of consistency (e.g., the item "perfect" from the NGS was instead presented as "I am perfect"). A random number generator was used to randomize the pool of items. Participants rated their agreement with each item on the same 1 (Strongly disagree) to 5 (Strongly agree) scale.

After data collection was complete, seven pairs of identically worded items were identified in the item set. In each case the response to the item presented to participants first was retained while the second was omitted. All remaining items were correlated with one another to identify excessively overlapping items. Two hundred and twenty-two item pairs were identified 
STRUCTURE OF NARCISSISM

with correlations greater than .65 (see Crowe et al., 2017 for description of similar method).

Individual items were removed from the overlapping set in a step-wise fashion intended to minimize bias and maximize the final number of retained items. Scale descriptive statistics and their representation in the final item pool are presented in supplemental materials (Supplemental Table 1).

All factor solutions were identified using a Principal Axis factoring method. ${ }^{1}$ A single unrotated factor was extracted, then rotated solutions of successively more factors were extracted until one of the factors was either too specific to be meaningful (e.g., a factor composed of the single item "I am a bit of a daredevil") or was no longer interpretable. All rotated solutions were identified using a Promax rotation. At each step in the process the factor scores were saved so that factor solutions from different levels could be correlated and compared. The identified factors were correlated with existing narcissism scales and other relevant criterion variables.

In addition, a series of three exploratory analyses were conducted to examine both the robustness of the factor solutions and the extent to which the identified factors represent constructs specific to narcissism rather than general personality traits. In the first, all items with loadings of less than .4 on both of the first two-factors were removed to test the structure when content that lies on the periphery of the grandiose and vulnerable narcissism domains is removed. This process removed 50 of the 215 items, resulting in a pool of 165 . In the second analysis, the three authors independently rated each item for its specificity to narcissism on a scale of 1 (narcissism-specific) to 3 (general trait content). After independently rating each item, sum-scores were calculated. Items with scores of 3-5 (e.g., "I only associate with people of my

\footnotetext{
${ }^{1}$ All factor analyses were replicated using alternative estimation methods and the solutions were consistent. Congruence coefficients comparing the principal axis factors to those estimated using maximum likelihood and principal components identified congruence greater than .98 through the six-factor solution.
} 
STRUCTURE OF NARCISSISM

caliber"; "I feel enraged when people disrespect me") were included in the narcissism-specific item pool while items with scores of 7-9 (e.g., "I am assertive"; "I feel foolish when I make a

mistake in front of others") were removed. The authors met to discuss all items with a score of 6 (i.e., a rating of 2-2-2 or 1-2-3) until unanimous agreement on whether to include or exclude the item was reached. This process removed 86 of the 215 items (see Supplemental Table 3), resulting in a pool of 129 items. In the third, all FFNI items, which were written to capture narcissistic expressions of relevant traits from the FFM and could be expected to contain the most general trait variance, were removed and the structural analyses were repeated. This removed 42 of the 215 items, resulting in a pool of 173 . Factor analyses were replicated with each of these three subsets of the original item pool and the stability of the original factor structure was evaluated by correlating factor scores from each subset of items with those from the original solution.

\section{RESULTS}

The first unrotated factor accounted for $22 \%$ of the total variance. The first ten eigenvalues were as follows: $48.28,17.74,9.58,7.49,4.70,3.77,3.27,2.66,2.56$, and 2.38. Following the single-factor analysis a series of successively larger solutions were examined. While the intent of the analysis was to describe narcissism at many levels of analysis, several approaches were used to identify the optimal number of factors. A parallel analysis (Horn, 1965) suggested 12 factors. Velicer's minimum average partial (MAP) test indicated 21 factors, and examination of BIC values (Raftery, 1995) indicated seven factors.

In the nine-factor solution, no items had their highest loading on the ninth factor. The eight-factor solution was therefore the largest model given consideration. The content of the factor solutions was examined to evaluate both parsimony and interpretability of the factors. 
STRUCTURE OF NARCISSISM

Inspection of the seven and eight factor solutions revealed that in each there was one factor composed of a single item: "I am a bit of a daredevil." Those solutions were excluded due to their inclusion of such a specific factor. In the six-factor solution, a 10-item fantasy-related factor emerged. The seven strongest loading items for this factor included the word fantasy and the six strongest began with the phrase "I often fantasize about...". Such homogeneity in item content was interpreted as indicative of a bloated specific factor. A list of all items loading onto the sixth factor and their loadings is provided in supplemental materials (Supplemental Table 2). The content of each of the factors through the five-factor solution was interpretable and item loadings were generally high. The five-factor solution was chosen as the base of the hierarchical analysis. The five-factor solution accounted for $39 \%$ of the variance in narcissism scores. Inclusion of the sixth factor increased variance accounted for by $2 \%$.

\section{A Hierarchy of Narcissism Factors}

The final hierarchy from one to five factors is depicted in Figure 1. Loadings for all items are provided in Supplemental Table 3. To better understand the content of the factors, scores from each solution were correlated with each of the full scales collected for the narcissism item pool (Table 1), as well as the FFM domains and facets (Table 2). The correlations of all factor scores are reported in Supplemental Table 4 along with the relationship between each factor's FFM profile.

The first identified factor (F1.1) was labeled Narcissism as it represents what is most common to all of the item content. It revealed substantial associations with nearly all broad narcissism scales. Full-scale correlations ranged from $r=.55$ (HSNS) to $r=.94$ (FFNI Total) while facet-level correlations varied between $r=.12$ (FFNI Shame) and $r=.85$ (PID-5 Grandiosity). When evaluated using the FFM traits, the narcissism factor was characterized by 
STRUCTURE OF NARCISSISM

low agreeableness (e.g., Morality $r=-.62$; Modesty $r=-.62$ ) and a moderate association with extraversion (e.g., Excitement Seeking $r=.36$; Assertiveness $r=.35$ ).

The two-factor solution revealed two correlated $(r=.42)$ factors consistent with grandiose and vulnerable narcissism. The highest loading items for the Grandiose Narcissism factor (F2.1) were primarily related to a grandiose sense of self (e.g., "I am superior"; "I have outstanding qualities few others possess"). Grandiose Narcissism (F2.1) also revealed a FFM pattern of associations consistent with grandiose narcissism - low agreeableness (e.g., Modesty $r$ $=-.73$; Morality $r=-.53$ ) and high extraversion (e.g., Assertiveness $r=.54$; Gregariousness $r=$ .41 ; Excitement Seeking $r=.40$ ). The most representative items for the Vulnerable Narcissism factor (F2.2) were primarily drawn from the PNI and included reactive anger (e.g., "I typically get very angry when I'm unable to get what I want from others"), and a dependence on others for validation ("It's hard to feel good about myself unless I know other people admire me"; "I very much need other people to take notice of more or compliment me"). From a personality perspective, Vulnerable Narcissism (F2.2) was characterized by strong positive associations with neuroticism (e.g., Anxiety $r=.52$; Depression $r=.52$; Anger $r=.49$ ) and a negative association with agreeableness (e.g., Morality $r=-.52$ ).

The third level of analysis revealed a factor solution consistent with Miller and colleagues' $(2016,2017)$ trifurcated model. ${ }^{2}$ Content from both Grandiose (F2.1) and Vulnerable (F2.2) Narcissism merged to yield a new factor labeled Self-centered Antagonism (F3.3). The three factors had moderate to large intercorrelations: $r=.28$ (F3.1 and F3.2), $r=.39$ (F3.2 and F3.3), and $r=.50$ (F3.1 and F3.3). Self-centered Antagonism (F3.3) included items related to a

\footnotetext{
${ }^{2}$ The factors observed at the three-factor level appear consistent with the three-factor structure of the FFNI (i.e., Agentic Extraversion, Antagonism, Neuroticism). The factor labels were modified slightly to reflect the belief that these traits are specific expressions of general personality domains.
} 
STRUCTURE OF NARCISSISM

willingness to exploit others for personal gain (e.g. "It's fine to take advantage of persons to get ahead), a sense of entitlement (e.g., "To be honest, I'm just more important than other people), and a lack of empathy (e.g., "I'm not big on feelings of sympathy"). Self-centered Antagonism's (F3.3) FFM profile included negative associations with all facets of agreeableness (e.g., Morality $r=-.63$; Cooperation $r=-.57)$ as well as a negative association with Dutifulness $(r=-.53)$, a facet of conscientiousness. The other two factors that emerged at this stage of analysis (F3.1 and F3.2) revealed patterns of association highly similar to their counterparts at the two-factor level. Factor 3.1 was labeled Agentic Extraversion and its strongest FFM correlates were Modesty $(r=$ -.69) and Assertiveness $(r=.60)$. Factor 3.2 was labeled Narcissistic Neuroticism as its strongest FFM associations were with facets of Neuroticism (e.g., Anxiety $r=.60$; Depression $r=.59$ ).

When four factors were extracted the three previously identified factors remained intact and yielded virtually identical factors (Agentic Extraversion, F4.1; Narcissistic Neuroticism, F4.2; Self-centered Antagonism, F4.3) and trait-based correlational profiles. Factor intercorrelations ranged from unrelated $(r=.01 ; \mathrm{F} 4.2$ and F4.4) to large $(r=.50 ; \mathrm{F} 4.1$ and F4.3). The fourth factor that emerged at this level was labeled Distrustful Self-reliance (F4.4) as it included items emphasizing a desire for self-sufficiency (e.g., "I don't like to depend on other people to do things"; "I hate asking for help"), and a hesitancy to trust others (e.g., "I'm slow to trust people"; "I often think others aren't telling me the whole truth"). Only 12 items had their highest loading on this factor, making it small in terms of item count. At this level of analysis Factors 4.1, 4.2, and 4.3 had 88, 54, and 61 indicators respectively. Of Factor 4.4's 12 indicators, only 4 had loadings greater than .50 and the median loading was .46. This factor also had a greater number of negatively loading items than the rest of the factors. While the majority of the negative loadings were small in magnitude (median $=-.07$ ), four items related to avoidance of 
STRUCTURE OF NARCISSISM

attention had associations stronger than -.3, the greatest being: "I hate being the center of attention" (reverse scored; $\lambda=-.38$ ). Distrustful Self-reliance was also unique in that it manifested null to small associations with the other narcissism factors (F4.1 $r=.03 ; \mathrm{F} 4.2 r=.01$; F4.3 $r=.10)$ and had a minimal association with the first narcissism factor $(r=.10)$. F4.4 factor scores correlated at a level greater than $r=|.40|$ with only three narcissism scales (GNS Selfsufficiency; FFNI Distrust $r=.56$; PNI Hiding the Self $r=.55$ ) and had relatively weaker associations with facets of the FFM, with only the agreeableness facet Trust showing a large association $(r=-.49)$.

Extracting five factors yielded two factors (i.e., Narcissistic Neuroticism F5.2; Selfcentered Antagonism F5.3) that were near perfect correlates with counterparts at the four-factor level. The Distrustful Self-reliance (F5.4) factor was also highly consistent with its previous counterpart $(r=.92)$. Intercorrelations between the five factors ranged from $r=-.02$ (F5.4 and F5.5) to $r=.63$ (F5.1 and F5.5). The two new factors emerged from Agentic Extraversion (F4.1) and were labeled Grandiosity (F5.1) and Attention Seeking (F5.5). Grandiosity (F5.1) was best represented by items related to a grandiose sense of self (e.g., "I deserve to be seen as a great personality") and entitlement (e.g., "great things should come to me”). Grandiosity’s (F5.1) strongest FFM facet-level correlates were Modesty $(r=-.65)$ and Assertiveness $(r=.45)$. Attention-seeking (F5.5) was composed of items related to a desire for attention (e.g., "I love getting the attention of other people"; "I can be a showoff") and authority (e.g., "I like having authority over people"; "I have a natural talent for influencing people”). Like Grandiosity (F5.1), Attention-seeking's (F5.5) strongest FFM correlates were Assertiveness $(r=.67)$ and Modesty $(r$ $=-.59$ ). While the factors identified at the five-factor level are generally distinct (Median interfactor $r=.22)$, Grandiosity (F5.1) and Attention-seeking (F5.5) factor scores covaried strongly $(r$ 
STRUCTURE OF NARCISSISM

$=.63)$ and had highly related personality trait (FFM) correlation profiles $(r=.97)$, suggesting that this level of branching may not be substantive enough to support the notion that they are meaningfully different factors.

\section{Criterion Associations across Factor Solutions}

In order to evaluate factor divergence, each factor score was correlated with relevant criterion variables: self-esteem, externalizing behaviors, and emotional distress (see Table 4). Meaningful divergence was observed within all factor solutions. Grandiose (F2.1) and Vulnerable (F2.2) Narcissism diverged in their relationship with self-esteem $\left(r_{\mathrm{F} 2.1}=.31, r_{\mathrm{F} 2.2}=\right.$ $.53)$ and emotional distress $\left(r_{\mathrm{F} 2.1}=-.20, r_{\mathrm{F} 2.2}=.50\right)$. Meaningful factor divergence was also observed for proactive and reactive aggression. Proactive aggression was comparable across factors at the two-factor level: Grandiose (F2.1) $r=.28$, Vulnerable (F2.2) $r=.32$. However, when three or more factors were extracted, Self-centered Antagonism (F3.3 $r=.43 ; \mathrm{F} 4.3 r=.44$; F5.3 $r=.45)$ revealed a particularly strong association relative to all other factors. Reactive aggression, on the other hand, showed a consistently stronger association with Vulnerable Narcissism (F2.2 $r=.37)$ and Narcissistic Neuroticism (F3.2 $r=.36 ;$ F4.2 $r=.35 ;$ F5.2 $r=.34)$. Distrustful self-reliance (F4.4 $r=.17$; F5.4 $r=.24$ ) was also more relevant to reactive aggression as its association increased to a level comparable to that of Antagonism (F4.3 $r=23$; F5.3 $r=$ .23). While some statistically significant inter-factor divergence was observed in associations with the externalizing behavior scales, the magnitude of all correlations was small. Distrustful Self-reliance (F5.4) was the only factor to show a significant correlation with substance use $(r=$ .13), but its relations did not differ meaningfully from nearly all other factors. The correlations with antisocial behavior at the five-factor level reveal Antagonism (F5.3; $r=.16)$, Distrustful Self-reliance $(\mathrm{F} 5.4 ; r=.14)$, and Attention-seeking $(\mathrm{F} 5.5 ; r=.16)$ as significant correlates, but 
STRUCTURE OF NARCISSISM

Attention-seeking (F5.5) and Grandiosity (F5.1) were the only factors with correlations

meaningfully different in magnitude. That was the only criterion association in which F5.1 and F5.5 diverged. No factors diverged in their association with intimate partner violence.

\section{Tests of Factor Robustness}

The first test of factor robustness removed items without substantial loadings on either the Grandiose (F2.1) or Vulnerable (F2.2) narcissism factors. Factor scores were highly stable ( $r s$ $>$.97) through the three-factor solution, but two novel factors emerged within the four- and fivefactor solutions. An attention seeking factor (e.g., "I make myself the center of attention"; "I love getting the attention of other people") was observed at the four-factor and five-factor level in place of the Distrustful Self-reliance (F4.4) factor, which did not replicate ( $r=-.55$ with F4.4; $r=$ -.58 with F5.4). At the five-factor level, a novel social dominance factor (e.g., "I am dominant"; "I have a natural talent for influencing people"; "I see myself as a good leader") emerged that was highly associated with the Attention Seeking factor ( $r=.89$ with F5.5). All other factor score correlations were greater than or equal to .96 .

In the second analysis of factor robustness, items judged to be non-specific to narcissism were removed (see Supplemental Table 3 for full list of items removed and retained). Factors consistent with Grandiose Narcissism (F2.1), Agentic Extraversion (F3.1, F4.1), Self-centered Antagonism (F3.3, F4.3, F5.3), and Grandiosity (F5.1) emerged at their respective levels ( $r s>$ .95). Shifts in the content of other factors emerged. At the two-factor level, the vulnerable narcissism factor was comparable, albeit smaller by item count ( $r=.88$ with F2.2) to the factor in the original analyses. At the three-factor level, an attention seeking factor was observed in place of the more general Narcissistic Neuroticism (F3.2) factor ( $r=.68$ with F3.2). The attention seeking factor persisted into the four-factor solution in place of the Distrustful Self-reliance 
STRUCTURE OF NARCISSISM

(F4.4) factor ( $r=-.52$ with F4.4). The four-factor solution also included a factor emphasizing negative emotionality in the form of reactive and entitled anger (i.e., "It irritates me when people don't notice how good a person I am"; "It really makes me angry when I don't get what I deserve"), grandiose fantasies (i.e., "I often fantasize about having lots of success and power") and contingent self-esteem (i.e., "I need others to acknowledge me"). While not identical, it was comparable with the Narcissistic Neuroticism factor from this level of the original solution ( $r=$ .85 with F4.2). The five-factor solution for this item pool yielded an uninterpretable factor.

The final test of factor robustness removed all FFNI items from the item pool. No change in factor structure was observed as all factors emerged in a manner consistent with the original analyses $(r s>.96)$.

\section{DISCUSSION}

Underlying structures of narcissism have been proposed previously, but most have been theoretically driven or more limited in scope (e.g., Miller et al., 2016; Pincus et al., 2009; Wink, 1991). There appears to be some degree of consensus among narcissism researchers that antagonism and entitlement are defining features of the domain (Campbell \& Miller, 2013; Krizan \& Herlache, 2018; Pincus et al., 2009; Wright \& Edershile, 2018). This is made clear by the consistency with which such content appears across the range of narcissism measures. What additional factors should be incorporated, however, has been a major source of contention and the basis for the now well-known distinction between grandiose and vulnerable narcissistic expressions. However, if grandiose and vulnerable narcissism are simply divergent expressions of a single broader pathology, an underlying structural model that can account for both expressions must be present. Three-factor models that can account for grandiose and vulnerable 
STRUCTURE OF NARCISSISM

profiles have been proposed (Krizan \& Herlache, 2018; Miller, Lynam, McCain, et al., 2016), but they may not fully describe the domain.

The goal of the present analysis was to empirically identify and describe a structural model of narcissism that accounts for both grandiose and vulnerable expressions. The "Bassackward" factor-analytic approach was used to describe narcissism's factor structure at a range of bandwidths, rather a single level of analysis. This approach allows for a more comprehensive understanding of the factor space and where current measures fall within it. Although the intent of the analysis was not to identify a "correct" number of factors, a base of the hierarchy did have to be selected. To that end, factor content was evaluated with the goal of balancing parsimony with coverage and the five-factor solution was identified as a reasonable base for analysis.

\section{Structure of Narcissism}

These analyses build upon previous work by using a more comprehensive item pool and more flexible analyses. The first factor (F1.1) was characterized by entitlement, antagonism, and grandiosity. This factor was consistent with the expectation that facets relevant to antagonistic and entitled behaviors are likely to be the common thread that runs through all conceptualizations of narcissism. From a trait perspective, this factor was most strongly related to the domains of agreeableness and extraversion, consistent with expert rating, clinician ratings, and lay public conceptualizations of narcissism and NPD (Lynam \& Widiger, 2001; Miller, Lynam, Siedor, Crowe, \& Campbell, 2018; Samuel \& Widiger, 2004).

Extracting two factors from the item pool revealed grandiose and vulnerable factors with nomological networks consistent with those previously established (Miller, Gentile, \& Campbell, 2013; Miller et al., 2014; Miller, Hoffman, et al., 2011; Thomas, Wright, Lukowitsky, Donnellan, \& Hopwood, 2012). Grandiose Narcissism (F2.1) was characterized by high 
STRUCTURE OF NARCISSISM

extraversion (e.g., gregariousness, assertiveness) and low agreeableness (e.g., morality, modesty). Vulnerable Narcissism (F2.2) was characterized by high neuroticism and low agreeableness (e.g., morality, cooperation). Tests of factor robustness indicated that this grandiose and vulnerable distinction is highly stable even with substantial modifications to the item pool. The two factors manifested FFM trait profiles consistent with the literature on these dimensions of narcissism ( $r$ s of .94 and .90 with meta-analytic profiles of grandiose and vulnerable narcissism, respectively; Campbell \& Miller, 2013).

Previous analyses attempting to identify a unified narcissism structure have argued for similar three-factor models (Krizan \& Herlache, 2018; Miller, Lynam, McCain, et al., 2016). These models identified the unique components of grandiose (e.g., immodesty, assertiveness) and vulnerable narcissism (e.g., emotional vulnerability) as well as a central factor that was common to both expressions. The trifurcated model identified antagonism (Miller et al., 2016) as core while the Narcissistic Spectrum Model identifies a somewhat more narrowly defined trait, entitled self-importance (Krizan \& Herlache, 2018). The observed structure is consistent with these models as Agentic Extraversion (F3.1) and Narcissistic Neuroticism (F3.2) are consistent with the peripheral factors that have been previously suggested. However, the differing bandwidths of the third "core" factor proposed in previous models yield competing hypotheses regarding the third factor. The third factor identified here (Self-centered Antagonism; F3.3) seems to be more comparable to the Antagonism factor of the trifurcated model (Miller et al., 2016) as the two constructs were nearly identical. This more broadly defined third factor persisted even after modifications were made to the item pool to capture a more narrowly defined narcissism domain. This finding alone does not preclude the accuracy of the Narcissism Spectrum Model as entitlement would be considered by most a facet of a broader antagonism 
STRUCTURE OF NARCISSISM

domain. In this case, however, most measures of entitlement revealed associations with Agentic

Extraversion (F3.1) that were equal or greater than their association with Antagonism (F3.3). It is possible that the three-factor model observed here is a slightly different rotation than that proposed by the Narcissistic Spectrum Model, and that entitlement is a facet of narcissism that covaries with both Agentic Extraversion (F3.1) and Antagonism (F3.3). In that case, an entitlement facet that accounted for some of the substantial covariation between Agentic Extraversion and Antagonism would be expected to emerge within the hierarchy. No such factor emerged. A final possible explanation is that entitlement (i.e., the expectation of special treatment) is an extension or downstream consequence of grandiosity (i.e., the belief that one is special). Near perfect covariation between grandiosity and entitlement would result in a single shared factor, but studies using individual measures of grandiosity and entitlement have indicated that while the constructs covary, they are not identical (Brown, Budzek, \& Tamborski, 2009; Campbell et al., 2004; Crowe et al., 2016).

While only narcissism scales were included in the present item pool, the three factors observed here are consistent with more general and broader personality traits. This result holds even when we attempt to eliminate items that are not narcissism specific. We believe that this is less a problem with measurement specificity than it is an illustration of the nature of trait covariation. Elevation in any one facet of Agreeableness is associated with elevations in the others. Individuals prone to callousness are also more likely to endorse other forms of antagonistic behavior (e.g., combativeness, immorality, arrogance). Due to the coherence of Agreeableness, it is very unlikely for an individual to score high on only a single aspect of antagonism. The same is true for facets of Extraversion and Neuroticism. It is therefore natural that factors similar to these trait domains would emerge. 
STRUCTURE OF NARCISSISM

It is our view that narcissism is underlain by low Agreeableness and may be especially characterized by arrogance and exploitativeness. Other pathological personality composites, such as psychopathy, are similarly underlain by antagonism but may emphasize different antagonismrelated facets (e.g., more callousness than grandiosity). The covariation of lower-order facets of antagonism, however, does suggest a limit to how specifically one can measure Agreeableness across constructs (i.e., if one scores high on grandiosity, one is also likely to score high on callousness). As such, narcissistic antagonism and psychopathic antagonism will likely look much the same. However, that is not to say that any measure of Agreeableness is equally valid for measuring antagonism as it is expressed within narcissism (what we refer to as Self-centered Antagonism; see Miller, Gaughan, Maples, \& Price, 2011). While these analyses suggest that narcissism can be captured with general trait domains, use of narcissism-specific scales directed at capturing particular presentations of general traits are likely to increase measurement precision.

Together, the three traits identified here yield an accurate measurement of narcissism domains. When compared to the FFM meta-analytic profile of grandiose and vulnerable narcissism (Campbell \& Miller, 2013), Self-centered Antagonism's (F3.3) FFM correlational profile was near equally related to both expressions: grandiose $(r=.49)$ and vulnerable $\operatorname{narcissism}(r=.62)$, consistent with the notion that antagonism is the "glue" that holds the narcissism dimensions together. Conversely, the Agentic Extraversion (F3.1) trait profile was strongly related to the meta-analytic profile for grandiose narcissism $(r=.91)$ but negatively related to the meta-analytic profile for vulnerable narcissism $(r=-.45)$. Similarly, Narcissistic Neuroticism (F3.2) demonstrated an FFM profile aligned with the meta-analytic profile for vulnerable but not grandiose narcissism ( $r \mathrm{~s}=.91$ and -.15 , respectively). 
STRUCTURE OF NARCISSISM

The three-factor solution was the final extraction on which explicit evidence-based hypotheses could be made. The four-factor solution identified a Distrustful Self-reliance (F4.4) factor that had no clear associations with any other factors in the narcissism domain. This factor was characterized by both the intention to independently manage one's own affairs as well as a fundamental distrust of the intentions and good nature of others. The factor was small by item count and had several small- to moderately-sized associations with a desire to avoid attention, but the primary loading of such items fell onto the Agentic Extraversion (F4.1) factor. The dearth of items could indicate that the factor does not belong within the construct, is under-represented within the most popular narcissism scales, or is a bloated specific factor that should not be interpreted as an equally large and meaningful component of narcissism as the other three identified factors. Distrust (from the FFNI) and Self-sufficiency (from the GNS), the factor's two strongest correlates, are both relatively unique in item content. The factor's null association with other components of narcissism as well as the general narcissism factor (F1.1) indicate that it may be better conceptualized as falling outside the scope of the narcissism domain. However, empirical support has been found for the relevance of Trust (vs. Distrust) to the FFM Agreeableness domain (Crowe et al., 2017), as well as the narcissism construct. Low trust in others has been rated as characteristic of NPD by expert academicians (Lynam \& Widiger, 2001), clinicians (Samuel \& Widiger, 2004), and the lay public (Miller et al., 2018). It is therefore surprising both that it is so poorly represented across narcissism scales and that it does not have stronger covariation with other components of the construct. Further research is necessary to evaluate what role, if any, Distrustful Self-reliance (F4.4, F5.4) plays within narcissism's factor structure. 
STRUCTURE OF NARCISSISM

At the five-factor level Agentic Extraversion (F4.1) split to yield Grandiosity (F5.1) and Attention-seeking (F5.5). These factors are comparable to the PID-5 traits identified as indicative of NPD. Although the content of these factors is distinguishable, the extent to which Grandiosity (F5.1) and Attention-seeking (F5.5) represent unique constructs is open for debate. They have a near-identical pattern of association with the FFM facets and their factor scores are strongly correlated. Among the few criterion variables that were collected, only a single divergent relationship (correlation with antisocial behavior) was observed. Grandiosity (F5.1) indicates that a grandiose sense of superiority (i.e., grandiosity) and an expectation of special treatment (i.e., entitlement) are components of the same factor. Given this association, it is no surprise that Grandiosity (F5.1) and Self-centered Antagonism (F5.3) are so highly correlated. It is notable that most factors at this level of analysis maintain relatively broad coverage, especially when compared to the faceted scales in active use. Narcissistic Neuroticism (F5.2) and Self-centered Antagonism (F5.3) are stable factors broad enough to account for much of the variance in their FFM counterparts. Distrustful Self-reliance (F5.4) and Attention Seeking (F5.5) are more narrowly defined, but the value of these unique factors in terms of additional prediction power is as yet unestablished.

It must be emphasized again here that the validity of this method is dependent on the content of the item pool and its ability to cover the breadth of the narcissism domain. All components of narcissism are assumed to be included within the item pool. Given the use of a wide variety of commonly used narcissism measures, many of which were developed from discrepant perspectives on this construct, this seems to be a reasonable assumption. By selecting every major narcissism scale, available at the time of this manuscript, the construct has been well represented in a form consistent with its use in the field today. 
STRUCTURE OF NARCISSISM

\section{Criterion Associations and Assessment Implications}

These analyses indicate that within the diversity of narcissism scales and subscales, there lies a relatively parsimonious factor structure. As with any hierarchical factor model, the best level of analysis is going to be dependent on the research question at hand. These analyses highlight levels of analysis that could reasonably be considered by correlating the narcissism factors with several relevant criterion variables. A one-factor narcissism solution has been generally ruled out for most contexts since the recognition of grandiose and vulnerable narcissisms' divergent nomological nets (Dickinson \& Pincus, 2003; Miller, Hoffman, et al., 2011; Wink, 1991). These analyses replicate that finding. Narcissism's (F1.1) null association with self-esteem and emotional distress masks substantial divergence at the two-factor level.

Much of the narcissism research currently being conducted occurs at the two-factor level with separate measures of grandiose and vulnerable narcissism. This level of analysis allows researchers to account for many of the divergent patterns of association between grandiose and vulnerable narcissism, but it fails to separate out the core component of the domain. For example, at the two-factor level grandiose and vulnerable narcissism have comparable associations with proactive aggression $(r \approx .30)$. Without measuring self-centered antagonism, a researcher has no means of evaluating the effects of grandiosity or vulnerability relative to the antagonistic interpersonal style shared between them. Only at the three-factor level can these effects be parsed apart, allowing, for example, a recognition that while self-centered antagonism accounts for some of the shared relationship with proactive aggression, the phenotype-specific components each maintain small associations with the construct as well.

The three-factor level of analysis may be a necessary level of specificity. Limiting analyses to only two factors hides relevant divergence in self-esteem, aggression, and emotional 
STRUCTURE OF NARCISSISM

distress that is observed at three factors and beyond. As the field progresses towards evaluating the stability of narcissism's expressions, it may be necessary to account for grandiose and vulnerable narcissism's shared association with antagonism to accurately evaluate the extent to which the expression-specific factors covary across time. The value of factors beyond the threefactor level (i.e., Distrustful Self-reliance, F4.4; Grandiosity, F5.1; Attention-Seeking, F5.5) are less clear. Distrustful Self-reliance seems generally unrelated to the narcissism domain and shows little divergence among the few criterion variables collected in these analyses. However, the factor does appear to be internally consistent and is found in several expert conceptualizations of the construct. Separating Agentic Extraversion (F4.1) into unique constructs (i.e., Grandiosity, F5.1; Attention-seeking, F5.5) is consistent with arguments for the use of homogeneous facets (Smith et al., 2009), but the magnitude of their covariance and similarity of their nomological nets may favor the more parsimonious Agentic Extraversion (F3.1) factor. Additional analyses with a more diverse range of criterion may be necessary to evaluate the necessity of the fourth and fifth factors.

Regardless of factor level, these analyses show that there are a range of applicable measures currently available for each factor, but all similarly labeled measures do not assess the same construct, at least not to the same degree. If interested in measuring a single narcissism construct, the FFNI-SF total score is a strong candidate appropriate, or, for a somewhat shorter measure, the NARQ, SCID-II NPD, and PID-5 NPD total scores seem equally effective. The single measure most closely associated with Grandiose Narcissism (F2.1) was the NPI total score, providing further support to the literature on the NPI's continued validity and function (e.g., Miller et al., 2014; Miller, Lynam, \& Campbell, 2016). The FFNI-SF Grandiose subscale, NGS, and NARQ Admiration subscale also effectively capture this level of the domain. The 
STRUCTURE OF NARCISSISM

NGS is particularly noteworthy in this regard given its brief form and ability to capture narcissistic grandiosity at both the trait and momentary state level (Edershile et al., 2018). Of similar interest is the Narcissistic Vulnerability Scale (Crowe, Edershile, et al., 2018). While not included in the full analyses, ${ }^{3}$ factor score correlations of the NVS (provided in Supplemental Table 5) provide support for its use as a measure of narcissistic vulnerability. Although the PNI does not seem sufficient for capturing the grandiosity construct, at least not without partialing PNI Vulnerability from it (Edershile, Simms, \& Wright, in press), the PNI vulnerability subscale and PNI total score were the strongest indicators of narcissistic vulnerability as it is defined by Factor 2.2. At the three-factor level the NPI continued to be the best indicator of Agentic Extraversion. Other options for this level of analysis include the NARQ Admiration subscale, the NGS, NPI L/A subscale, SD3 Narcissism scale, and FFNI Extraversion scale. The PNI Vulnerability subscale was the single best indicator of Narcissistic Neuroticism (F3.2). Additional measures for this construct include the PNI total score, FFNI Vulnerability subscale, and the PNI Contingent Self-esteem (CSE) subscale. FFNI Antagonism was the single best indicator of the Self-centered Antagonism (F3.3) factor. Other measures to consider for this level of analysis would include the SCID-II NPD scale and NARQ Rivalry scale.

\section{Limitations and Future Directions}

Although this study had a number of strengths including a large sample size, an inclusive collection of narcissism measures, and a focus on item-, rather than scale-level content, limitations must be acknowledged. The sample was composed entirely of MTurk participants. Reliance on online data collection methods has a number of advantages that make it among the most viable options for large questionnaire-based analyses (Chandler \& Shapiro, 2016; Miller,

\footnotetext{
${ }^{3}$ Sufficient validation of the NVS had not been completed at the time the bulk of these analyses were conducted. As such, we chose not to include the measure in the narcissism item pool.
} 
STRUCTURE OF NARCISSISM

Crowe, et al., 2017), but participants were somewhat homogeneous and limited to individuals residing within the United States. There is no guarantee that the structure identified here will replicate in other countries, cultures, or administration formats (i.e., paper and pencil).

Additional research is needed to test the generalizability of these results.

It should be acknowledged that the model identified in the present analyses is most accurately described as the structure of the 215 narcissism items included here. It is the nature of factor analyses to be contingent on the pool of included items. It is for that reason that we tried to be inclusive with regard to our scale selection. By beginning with a pool of over 300 items from a wide array of current, widely-used, narcissism scales, we believe we have successfully included all aspects of the construct as it is conceptualized in the contemporary literature. However, we did not include every narcissism scale. For example, we chose not to incorporate MMPI-derived scales referenced by Wink (1991) in his discussion of covert narcissism. This is a problem only to the extent that these omitted scales include content that is missing from the scales and items we did employ. If a trait component of narcissism was not represented in the current item pool, it could not have emerged as a factor in our analyses. We do believe that all potential facets of the domain, as it is currently conceptualized, were represented in the current item pool. For example, regarding the MMPI-based covert narcissism scales, the FFNI, HSNS, and PNI all have scales intended to measure narcissistic vulnerability.

The sole reliance on self-report measures is an additional limitation. It is possible that the strength of associations between identified factors and criterion measures are inflated due to shared method variance, but such inflation effects are likely offset by the imperfect reliability of the items (Chan, 2009). It is also possible that acquiescence or extreme response styles may have inflated the magnitude of correlations, and while the effect of acquiescence could not be directly 
STRUCTURE OF NARCISSISM

evaluated here, other analyses on similar samples have indicated minimal effect (Crowe et al., 2017).

The present analyses emphasized inclusion of a large set of narcissism items and was therefore limited in its ability to include a wide array of criterion measures. Future research should consider inclusion of a wider array of relevant criterion. Doing so will aid in evaluating patterns of convergence and divergence among the identified factors. In conclusion, the present study expands on previous work (Krizan \& Herlache, 2018; Miller, Lynam, et al., 2017; Miller, Lynam, McCain, et al., 2016) directed at identifying a unified structural model of narcissism. These results support previous findings and indicate that antagonism-related traits are the "core" of narcissistic pathologies (i.e., those traits shared by all expressions of the domain) while Agentic Extraversion (e.g., assertiveness, immodesty) and Narcissistic Neuroticism (e.g., emotional vulnerability) are traits specific to particular configurations of narcissism. Additional factors (i.e., Distrustful Self-reliance, Grandiosity, Attention-seeking) were identified but little evidence was generated in the present study for their importance. Additional analyses with a more diverse range of criterion variables will be necessary to determine if such factors should be incorporated into the model. 
STRUCTURE OF NARCISSISM

\section{Declaration of Conflicting Interests}

The author(s) declared no potential conflicts of interest with respect to the research, authorship, and/or publication of this article.

\section{Funding}

The author(s) received no financial support for the research, authorship, and/or publication of this article. 


\section{REFERENCES}

Back, M. D., Küfner, A. C., Dufner, M., Gerlach, T. M., Rauthmann, J. F., \& Denissen, J. J. (2013). Narcissistic admiration and rivalry: Disentangling the bright and dark sides of narcissism. Journal of Personality and Social Psychology, 105, 1013-1037.

Brown, R. P., Budzek, K., \& Tamborski, M. (2009). On the meaning and measure of narcissism. Personality and Social Psychology Bulletin, 35, 951-964.

Cain, N. M., Pincus, A. L., \& Ansell, E. B. (2008). Narcissism at the crossroads: Phenotypic description of pathological narcissism across clinical theory, social/personality psychology, and psychiatric diagnosis. Clinical Psychology Review, 28, 638-656.

Campbell, W. K., Bonacci, A. M., Shelton, J., Exline, J. J., \& Bushman, B. J. (2004).

Psychological entitlement: Interpersonal consequences and validation of a self-report measure. Journal of Personality Assessment, 83, 29-45.

Campbell, W. K., \& Miller, J. D. (2013). Narcissistic personality disorder and the five-factor model: Delineating narcissistic personality disorder, grandiose narcissism, and vulnerable narcissism. In T. A. Widiger \& P. T. Costa Jr. (Eds.), Personality disorders and the fivefactor model of personality (3rd ed.). (pp. 133-145). Washington, DC US: American Psychological Association.

Chan, D. (2009). So why ask me? Are self-report data really that bad? In C. E. Lance \& R. J. Vandenberg (Eds.), Statistical and methodological myths and urban legends: Doctrine, verity and fable in the organizational and social sciences (pp. 309-336). New York, NY, US: Routledge/Taylor \& Francis Group.

Chandler, J., \& Shapiro, D. (2016). Conducting clinical research using crowdsourced convenience samples. Annual Review of Clinical Psychology, 12, 53-81. 
STRUCTURE OF NARCISSISM

Crowe, M. L., Carter, N. T., Campbell, W. K., \& Miller, J. D. (2016). Validation of the Narcissistic Grandiosity Scale and creation of reduced item variants. Psychological Assessment, 28, 1550-1560.

Crowe, M. L., Edershile, E. A., Wright, A. G. C., Campbell, W. K., Lynam, D. R., \& Miller, J. D. (2018). Development and validation of the narcissistic vulnerability scale: An adjective rating scale. Psychological Assessment, 30, 978-983.

Crowe, M. L., Lynam, D. R., \& Miller, J. D. (2018). Uncovering the structure of agreeableness from self-report measures. Journal of Personality, 86, 771-787.

Crowe, M. L., Sleep, C. E., Carter, N. T., Campbell, W. K., \& Miller, J. D. (2018). Self-esteem and narcissism: An item response theory analysis of curvilinearity. Personality and Individual Differences, 128, 16-20.

Dickinson, K. A., \& Pincus, A. L. (2003). Interpersonal analysis of grandiose and vulnerable narcissism. Journal of Personality Disorders, 17, 188-207.

Edershile, E. A., Woods, W. C., Sharpe, B. M., Crowe, M. L., Miller, J. D., \& Wright, A. G. C. (manuscript under review). A day in the life of narcissus: Measuring narcissistic grandiosity and vulnerability in daily life.

First, M. B., Gibbon, M., Spitzer, R. L., Williams, J. B., \& Benjamin, L. S. (1997). Structured clinical interview for DSM-IV personality disorders (SCID-II): Interview and questionnaire. Washington, D.C.: American Psychiatric Press.

Foster, J. D., McCain, J. L., Hibberts, M. F., Brunell, A. B., \& Johnson, R. B. (2015). The Grandiose Narcissism Scale: A global and facet-level measure of grandiose narcissism. Personality and Individual Differences, 73, 12-16. 
STRUCTURE OF NARCISSISM

Glover, N., Miller, J. D., Lynam, D. R., Crego, C., \& Widiger, T. A. (2012). The five-factor narcissism inventory: A five-factor measure of narcissistic personality traits. Journal of Personality Assessment, 94, 500-512.

Goldberg, L. R. (2006). Doing it all bass-ackwards: The development of hierarchical factor structures from the top down. Journal of Research in Personality, 40(4), 347-358.

Hendin, H. M., \& Cheek, J. M. (1997). Assessing hypersensitive narcissism: A reexamination of Murray's Narcism Scale. Journal of Research in Personality, 31, 588-599.

Horn, J. L. (1965). A rationale and test for the number of factors in factor analysis. Psychometrika, 30, 179-185.

Hyler, S. E. (1994). PDQ-4+ personality questionnaire. New York, NY: New York State Psychiatric Institute.

Jones, D. N., \& Paulhus, D. L. (2014). Introducing the Short Dark Triad (SD3) A Brief Measure of Dark Personality Traits. Assessment, 21, 28-41.

Krizan, Z., \& Herlache, A. D. (2018). The Narcissism Spectrum Model: A Synthetic View of Narcissistic Personality. Personality and Social Psychology Review, 22, 3-31.

Krueger, R. F., Derringer, J., Markon, K. E., Watson, D., \& Skodol, A. E. (2012). Initial construction of a maladaptive personality trait model and inventory for DSM-5. Psychological Medicine, 42, 1879-1890.

Lynam, D. R., Gaughan, E. T., Miller, J. D., Miller, D. J., Mullins-Sweatt, S., \& Widiger, T. A. (2011). Assessing the basic traits associated with psychopathy: development and validation of the Elemental Psychopathy Assessment. Psychological Assessment, 23, $108-124$. 
STRUCTURE OF NARCISSISM

Lynam, D. R., \& Widiger, T. A. (2001). Using the five-factor model to represent the DSM-IV personality disorders: An expert consensus approach. Journal of Abnormal Psychology, $110,401-412$.

Maples, J. L., Guan, L., Carter, N. T., \& Miller, J. D. (2014). A test of the International Personality Item Pool representation of the Revised NEO Personality Inventory and development of a 120-item IPIP-based measure of the five-factor model. Psychological Assessment, 26, 1070-1084.

Marsh, H. W., Lüdtke, O., Nagengast, B., Morin, A. J., \& Von Davier, M. (2013). Why item parcels are (almost) never appropriate: Two wrongs do not make a right - Camouflaging misspecification with item parcels in CFA models. Psychological Methods, 18, 257-284.

Miller, J. D., \& Campbell, W. K. (2008). Comparing clinical and social-personality conceptualizations of narcissism. Journal of Personality, 76, 449-476.

Miller, J. D., Crowe, M. L., Weiss, B., Maples-Keller, J. L., \& Lynam, D. R. (2017). Using online, crowdsourcing platforms for data collection in personality disorder research: The example of Amazon's Mechanical Turk. Personality Disorders: Theory, Research, and Treatment, 8, 26-34.

Miller, J. D., Gaughan, E. T., Maples, J., \& Price, J. (2011). A comparison of Agreeableness scores from the Big Five Inventory and the NEO PI-R: Consequences for the study of narcissism and psychopathy. Assessment, 18, 335-339

Miller, J. D., Gentile, B., \& Campbell, W. K. (2013). A test of the construct validity of the FiveFactor Narcissism Inventory. Journal of Personality Assessment, 95, 377-387.

Miller, J. D., Gentile, B., Carter, N. T., Crowe, M., Hoffman, B. J., \& Campbell, W. K. (2018). A comparison of the nomological networks associated with forced-choice and likert formats 
STRUCTURE OF NARCISSISM

of the narcissistic personality inventory. Journal of Personality Assessment, 100, 259267.

Miller, J. D., Hoffman, B. J., Gaughan, E. T., Gentile, B., Maples, J., \& Keith Campbell, W. (2011). Grandiose and vulnerable narcissism: A nomological network analysis. Journal of Personality, 79, 1013-1042.

Miller, J. D., \& Lynam, D. R. (2003). Psychopathy and the Five-factor model of personality: A replication and extension. Journal of Personality Assessment, 81, 168-178.

Miller, J. D., Lynam, D. R., \& Campbell, W. K. (2016). Measures of narcissism and their relations to DSM-5 pathological traits: A critical reappraisal. Assessment, 23, 3-9.

Miller, J. D., Lynam, D. R., Hyatt, C. S., \& Campbell, W. K. (2017). Controversies in narcissism. Annual Review of Clinical Psychology, 13, 291-315.

Miller, J. D., Lynam, D. R., McCain, J. L., Few, L. R., Crego, C., Widiger, T. A., \& Campbell, W. K. (2016). Thinking structurally about narcissism: An examination of the Five-Factor Narcissism Inventory and its components. Journal of Personality Disorders, 30, 1-18.

Miller, J. D., Lynam, D. R., Siedor, L., Crowe, M., \& Campbell, W. K. (2018). Consensual lay profiles of narcissism and their connection to the Five-Factor Narcissism Inventory. Psychological Assessment, 30, 10-18.

Miller, J. D., Lynam, D. R., Vize, C., Crowe, M., Sleep, C., Maples-Keller, J. L., ... Campbell, W. K. (2018). Vulnerable narcissism is (mostly) a disorder of neuroticism. Journal of Personality, 86.

Miller, J. D., Maples, J., \& Campbell, W. K. (2011). Comparing the construct validity of scales derived from the Narcissistic Personality Inventory: A reply to Rosenthal and Hooley (2010). Journal of Research in Personality, 45, 401-407. 
STRUCTURE OF NARCISSISM

Miller, J. D., McCain, J., Lynam, D. R., Few, L. R., Gentile, B., MacKillop, J., \& Keith, W. (2014). A comparison of the criterion validity of popular measures of narcissism and narcissistic personality disorder via the use of expert ratings. Psychological Assessment, $26,958-969$.

Miller, J. D., Price, J., \& Campbell, W. K. (2012). Is the narcissistic personality inventory still relevant? A test of independent grandiosity and entitlement scales in the assessment of narcissism. Assessment, 19, 8-13.

Morf, C. C., \& Rhodewalt, F. (2001). Unraveling the paradoxes of narcissism: A dynamic selfregulatory processing model. Psychological Inquiry, 12, 177-196.

Pilkonis, P. A., Choi, S. W., Reise, S. P., Stover, A. M., Riley, W. T., \& Cella, D. (2011). Item Banks for Measuring Emotional Distress From the Patient-Reported Outcomes Measurement Information System (PROMIS®): Depression, Anxiety, and Anger. Assessment, 18, 263-283.

Pincus, A. L., Ansell, E. B., Pimentel, C. A., Cain, N. M., Wright, A. G., \& Levy, K. N. (2009). Initial construction and validation of the Pathological Narcissism Inventory. Psychological Assessment, 21, 365-379.

Pryor, L. R., Miller, J. D., \& Gaughan, E. T. (2008). A comparison of the Psychological Entitlement Scale and the Narcissistic Personality Inventory's Entitlement Scale: Relations with general personality traits and personality disorders. Journal of Personality Assessment, 90, 517-520.

Raftery, A. E. (1995). Bayesian model selection in social research. Sociological Methodology, 25, 111-163. 
STRUCTURE OF NARCISSISM

Raine, A., Dodge, K., Loeber, R., Gatzke-Kopp, L., Lynam, D., Reynolds, C., ... Liu, J. (2006). The Reactive-Proactive Aggression Questionnaire: Differential Correlates of Reactive and Proactive Aggression in Adolescent Boys. Aggressive Behavior, 32, 159-171.

Raskin, R., \& Terry, H. (1988). A principal-components analysis of the Narcissistic Personality Inventory and further evidence of its construct validity. Journal of Personality and Social Psychology, 54, 890-902.

Rosenberg, M. (1965). Society and the adolescent self-image. Princeton, N.J.: Princeton University Press.

Rosenthal, S. A., Hooley, J. M., \& Steshenko, Y. (2007). Distinguishing grandiosity from selfesteem: Development of the Narcissistic Grandiosity Scale. Unpublished Manuscript.

Samuel, D. B., \& Widiger, T. A. (2004). Clinicians' personality descriptions of prototypic personality disorders. Journal of Personality Disorders, 18, 286-308.

Schmitt, T. A., Sass, D. A., Chappelle, W., \& Thompson, W. (2018). Selecting the "Best" Factor Structure and Moving Measurement Validation Forward: An Illustration. Journal of Personality Assessment, 100, 345-362.

Sherman, E. D., Miller, J. D., Few, L. R., Campbell, W. K., Widiger, T. A., Crego, C., \& Lynam, D. R. (2015). Development of a short form of the Five-Factor Narcissism Inventory: The FFNI-SF. Psychological Assessment, 27, 1110-1116.

Smith, G. T., McCarthy, D. M., \& Zapolski, T. C. B. (2009). On the value of homogeneous constructs for construct validation, theory testing, and the description of psychopathology. Psychological Assessment, 21, 272-284. 
STRUCTURE OF NARCISSISM

Thomas, K. M., Wright, A. G., Lukowitsky, M. R., Donnellan, M. B., \& Hopwood, C. J. (2012). Evidence for the criterion validity and clinical utility of the Pathological Narcissism Inventory. Assessment, 19, 135-145.

Vize, C. E., Collison, K. L., Crowe, M. L., Campbell, W. K., Miller, J. D., \& Lynam, D. R. (2017). Using Dominance Analysis to Decompose Narcissism and Its Relation to Aggression and Externalizing Outcomes. Assessment. https://doi.org/10.1177/1073191116685811

Wink, P. (1991). Two faces of narcissism. Journal of Personality and Social Psychology, 61, $590-597$.

Wood, D., Gardner, M. H., \& Harms, P. D. (2015). How functionalist and process approaches to behavior can explain trait covariation. Psychological Review, 122, 84-111.

Wright, A. G. C., \& Edershile, E. A. (2018). Issues resolved and unresolved in pathological narcissism. Current Opinion in Psychology, 21, 74-79. 
STRUCTURE OF NARCISSISM

Table 1

Factor Score Correlations with Narcissism Scales

\begin{tabular}{|c|c|c|c|c|c|c|c|c|c|c|c|c|c|c|c|}
\hline & F1.1 & F2.1 & $\mathrm{F} 2.2$ & F3.1 & F3.2 & F3.3 & F4.1 & F4.2 & F4.3 & F4.4 & F5.1 & F5.2 & F5.3 & F5.4 & F5.5 \\
\hline FFNI Total & 0.94 & $0.84^{\mathrm{a}}$ & $0.73^{\mathrm{b}}$ & $0.80^{\mathrm{a}}$ & $0.57^{b}$ & $0.78^{\mathrm{a}}$ & $0.79^{\mathrm{a}}$ & $0.55^{\mathrm{b}}$ & $0.79^{\mathrm{a}}$ & $0.17^{\mathrm{c}}$ & $0.78^{\mathrm{a}}$ & $0.50^{\mathrm{b}}$ & $0.72^{\mathrm{a}, \mathrm{d}}$ & $0.27^{\mathrm{c}}$ & $0.67^{\mathrm{d}}$ \\
\hline Antagonism & $\underline{0.88}$ & $0.78^{\mathrm{a}}$ & $0.70^{\mathrm{b}}$ & $0.65^{\mathrm{a}}$ & $0.45^{\mathrm{b}}$ & $\underline{0.92^{\mathrm{c}}}$ & $0.64^{\mathrm{a}}$ & $0.43^{\mathrm{b}}$ & $\underline{0.92^{\mathrm{c}}}$ & $0.18^{\mathrm{d}}$ & $0.67^{\mathrm{a}}$ & $0.39^{\mathrm{b}}$ & $\underline{0.89^{c}}$ & $0.23^{\mathrm{d}}$ & $0.52^{\mathrm{e}}$ \\
\hline Extraversion & $\overline{0.76}$ & $0.82^{\mathrm{a}}$ & $0.34^{\mathrm{b}}$ & $0.89^{\mathrm{a}}$ & $0.31^{\mathrm{b}}$ & $\overline{0.35^{\mathrm{b}}}$ & $0.90^{\mathrm{a}}$ & $0.30^{\mathrm{b}}$ & $\overline{0.36^{\mathrm{b}}}$ & $0.01^{\mathrm{c}}$ & $0.80^{\mathrm{a}}$ & $0.23^{\mathrm{b}}$ & $\overline{0.26^{\mathrm{b}}}$ & $0.17^{b}$ & $\underline{0.83^{\mathrm{a}}}$ \\
\hline Neuroticism & 0.04 & $-0.27^{\mathrm{a}}$ & $0.58^{\mathrm{b}}$ & $-\overline{-0.18^{\mathrm{a}}}$ & $\underline{0.77^{b}}$ & $-0.06^{\mathrm{c}}$ & $-\overline{-0.17^{\mathrm{a}}}$ & $\underline{0.78^{b}}$ & $-0.04^{\mathrm{c}}$ & $-0.11^{\mathrm{a}, \mathrm{c}}$ & $-\overline{-0.15^{\mathrm{a}}}$ & $\underline{0.80^{b}}$ & $-0.02^{\mathrm{c}}$ & $-0.12^{\mathrm{a}, \mathrm{c}}$ & $-\overline{0.11^{\mathrm{a}}, \mathrm{c}}$ \\
\hline FFNI Grandiose & 0.90 & $0.93^{\mathrm{a}}$ & $0.47^{\mathrm{b}}$ & $0.88^{\mathrm{a}}$ & $0.27^{\mathrm{b}}$ & $0.74^{\mathrm{c}}$ & $0.87^{\mathrm{a}}$ & $0.25^{\mathrm{b}}$ & $0.74^{\mathrm{c}}$ & $0.08^{\mathrm{d}}$ & $0.82^{\mathrm{a}}$ & $0.19^{\mathrm{b}}$ & $0.67^{\mathrm{c}}$ & $0.19^{\mathrm{b}}$ & $0.76^{\mathrm{d}}$ \\
\hline Acclaim-seeking & 0.51 & $0.63^{\mathrm{a}}$ & $0.09^{\mathrm{b}}$ & $0.69^{\mathrm{a}}$ & $0.07^{\mathrm{b}}$ & $0.17^{\mathrm{b}}$ & $0.70^{\mathrm{a}}$ & $0.06^{\mathrm{b}}$ & $0.17^{\mathrm{b}, \mathrm{c}}$ & $0.21^{\mathrm{c}}$ & $0.66^{\mathrm{a}}$ & $0.01^{\mathrm{b}}$ & $0.07^{\mathrm{b}}$ & $\underline{0.30^{c}}$ & $0.55^{\mathrm{d}}$ \\
\hline Arrogance & 0.78 & $0.76^{\mathrm{a}}$ & $0.50^{\mathrm{b}}$ & $0.66^{\mathrm{a}}$ & $0.27^{\mathrm{b}}$ & $\underline{0.78^{c}}$ & $0.65^{\mathrm{a}}$ & $0.25^{\mathrm{b}}$ & $\underline{0.78^{\mathrm{c}}}$ & $0.12^{\mathrm{b}}$ & $0.71^{\mathrm{a}}$ & $0.22^{\mathrm{b}}$ & $\underline{0.73^{a}}$ & $\overline{0.09^{b}}$ & $0.43^{\mathrm{c}}$ \\
\hline Authoritativeness & 0.56 & $0.70^{\mathrm{a}}$ & $0.09^{\mathrm{b}}$ & $0.76^{\mathrm{a}}$ & $0.04^{\mathrm{b}}$ & $\overline{0.22^{\mathrm{c}}}$ & $0.76^{\mathrm{a}}$ & $0.04^{\mathrm{b}}$ & $\overline{0.24^{c}}$ & $0.00^{\mathrm{b}}$ & $0.61^{\mathrm{a}}$ & $-0.04^{b}$ & $\overline{0.15^{\mathrm{c}}}$ & $0.21^{\mathrm{c}}$ & $\underline{0.79^{d}}$ \\
\hline Entitlement & .78 & $0.74^{\mathrm{a}}$ & $0.54^{\mathrm{b}}$ & $0.66^{\mathrm{a}}$ & $0.34^{\mathrm{b}}$ & $0.74^{\mathrm{c}}$ & $0.65^{\mathrm{a}}$ & $0.32^{\mathrm{b}}$ & $0.75^{\mathrm{c}}$ & $-0.02^{\mathrm{d}}$ & $0.72^{\mathrm{a}}$ & $0.30^{\mathrm{b}}$ & $0.69^{\mathrm{a}}$ & $-0.08^{\mathrm{c}}$ & $\overline{0.43^{\mathrm{d}}}$ \\
\hline Exhibitionism & 0.61 & $0.61^{\mathrm{a}}$ & $0.36^{\mathrm{b}}$ & $0.68^{\mathrm{a}}$ & $0.36^{\mathrm{b}}$ & $0.26^{\mathrm{b}}$ & $0.68^{\mathrm{a}}$ & $0.38^{\mathrm{b}}$ & $0.29^{\mathrm{b}}$ & $-0.30^{\mathrm{c}}$ & $0.54^{\mathrm{a}}$ & $0.32^{\mathrm{b}}$ & $0.22^{\mathrm{b}}$ & $-0.12^{\mathrm{c}}$ & $0.77^{\mathrm{d}}$ \\
\hline Exploitativ & 0.68 & 0.59 & 0.55 & $0.46^{\mathrm{a}}$ & $0.31^{\mathrm{b}}$ & $\underline{0.79^{c}}$ & $0.45^{\mathrm{a}}$ & $0.30^{\mathrm{b}}$ & $\underline{0.80^{c}}$ & $-0.06^{\mathrm{d}}$ & $0.44^{\mathrm{a}}$ & $0.27^{\mathrm{b}}$ & $\underline{0.80^{\mathrm{c}}}$ & $-0.02^{\mathrm{d}}$ & $0.42^{\mathrm{a}}$ \\
\hline Grand. fantasies & 0.64 & 0.57 & 0.51 & $0.59^{\mathrm{a}}$ & $0.47^{\mathrm{b}}$ & $0.41^{\mathrm{b}}$ & $0.60^{\mathrm{a}}$ & $0.46^{\mathrm{b}}$ & $0.42^{\mathrm{b}}$ & $0.11^{\mathrm{c}}$ & $0.63^{\mathrm{a}}$ & $0.43^{\mathrm{b}}$ & $0.34^{\mathrm{b}}$ & $0.12^{\mathrm{c}}$ & $0.42^{\mathrm{b}}$ \\
\hline Indifference & 0.19 & $0.36^{\mathrm{a}}$ & $-0.19^{b}$ & $0.27^{\mathrm{a}}$ & $-0.39^{b}$ & $0.29^{\mathrm{a}}$ & $0.26^{\mathrm{a}}$ & $-0.41^{b}$ & $0.26^{\mathrm{a}}$ & $0.33^{a}$ & $0.27^{\mathrm{a}}$ & $-0.44^{b}$ & $0.25^{\mathrm{a}, \mathrm{c}}$ & $0.35^{\mathrm{a}}$ & $0.15^{\mathrm{c}}$ \\
\hline Lack & 0.42 & 0.36 & 0.35 & 0.17 & 0.08 & $0.72^{\mathrm{c}}$ & $0.16^{\mathrm{a}, \mathrm{b}}$ & $0.05^{\mathrm{a}}$ & $0.70^{\mathrm{c}}$ & $\overline{0.27^{\mathrm{b}}}$ & $0.22^{\mathrm{a}}$ & $0.05^{\mathrm{b}}$ & $0.73^{\mathrm{c}}$ & $\overline{0.25^{\mathrm{a}}}$ & $0.07^{\mathrm{b}}$ \\
\hline Man & 0.66 & $0.71^{\mathrm{a}}$ & $0.30^{\mathrm{b}}$ & $0.69^{\mathrm{a}}$ & $0.16^{\mathrm{b}}$ & $0.50^{\mathrm{c}}$ & $0.68^{\mathrm{a}}$ & $0.15^{\mathrm{b}}$ & $0.51^{\mathrm{c}}$ & $-0.04^{d}$ & $0.56^{\mathrm{a}}$ & $0.09^{\mathrm{b}}$ & $0.46^{\mathrm{c}}$ & $0.15^{\mathrm{b}}$ & $0.73^{\mathrm{d}}$ \\
\hline Thril & .46 & 0.43 & 0.33 & $0.37^{\mathrm{a}}$ & $0.21^{\mathrm{b}}$ & $0.45^{\mathrm{a}}$ & $0.37^{\mathrm{a}}$ & $0.21^{\mathrm{b}}$ & $0.46^{\mathrm{a}}$ & $-0.08^{\mathrm{c}}$ & $0.32^{\mathrm{a}}$ & $0.18^{\mathrm{b}}$ & $0.45^{\mathrm{c}}$ & $0.01^{\mathrm{d}}$ & $0.40^{\mathrm{c}}$ \\
\hline ulnerable & .40 & $0.07^{\mathrm{a}}$ & $0.84^{\mathrm{b}}$ & $0.08^{\mathrm{a}}$ & $0.88^{\mathrm{b}}$ & $0.36^{\mathrm{c}}$ & $0.09^{\mathrm{a}}$ & $0.87^{\mathrm{b}}$ & $0.36^{\mathrm{c}}$ & $0.28^{\mathrm{c}}$ & $0.16^{\mathrm{a}}$ & $0.88^{\mathrm{b}}$ & $0.36^{\mathrm{c}}$ & $0.28^{\mathrm{a}, \mathrm{c}}$ & $0.02^{\mathrm{d}}$ \\
\hline Distr & .29 & $0.13^{\mathrm{a}}$ & $0.46^{\mathrm{b}}$ & $0.08^{\mathrm{a}}$ & $0.40^{\mathrm{b}}$ & $0.36^{\mathrm{b}}$ & $0.08^{\mathrm{a}}$ & $0.37^{\mathrm{b}}$ & $0.33^{\mathrm{b}}$ & $\underline{0.56^{\mathrm{c}}}$ & $0.15^{\mathrm{a}}$ & $0.37^{\mathrm{b}}$ & $0.34^{\mathrm{b}}$ & $\underline{0.58^{\mathrm{c}}}$ & $-0.02^{\mathrm{d}}$ \\
\hline Need for Ad. & 0.19 & $-0.13^{\mathrm{a}}$ & $0.69^{b}$ & $-0.09^{\mathrm{a}}$ & $\underline{0.81^{\mathrm{b}}}$ & $0.14^{\mathrm{c}}$ & $-0.08^{\mathrm{a}}$ & $\underline{0.81^{b}}$ & $0.15^{\mathrm{c}}$ & $-0.01^{a}$ & $-0.04^{a}$ & $\underline{0.83^{b}}$ & $0.17^{\mathrm{c}}$ & $-0.03^{a}$ & $-0.06^{\mathrm{a}}$ \\
\hline e Anger & 0.62 & $0.42^{\mathrm{a}}$ & $\underline{0.73^{b}}$ & $0.37^{\mathrm{a}}$ & $\overline{0.64^{\mathrm{b}}}$ & $0.59^{\mathrm{b}}$ & $0.37^{\mathrm{a}}$ & $\overline{0.62^{b}}$ & $0.59^{\mathrm{b}}$ & $0.22^{\mathrm{c}}$ & $0.45^{\mathrm{a}}$ & $\overline{0.61^{\mathrm{b}}}$ & $0.57^{\mathrm{b}}$ & $0.20^{\mathrm{c}}$ & $0.22^{\mathrm{c}}$ \\
\hline Shame & 0.12 & $-0.17^{\mathrm{a}}$ & $\overline{0.60^{\mathrm{b}}}$ & $-0.10^{\mathrm{a}}$ & ${\underline{0.76^{b}}}^{b}$ & $0.02^{\mathrm{c}}$ & $-0.09^{\mathrm{a}}$ & $\underline{0.76^{\mathrm{b}}}$ & $0.03^{\mathrm{c}}$ & $0.08^{c}$ & $-0.05^{\mathrm{a}}$ & $\underline{0.77^{\mathrm{b}}}$ & $0.04^{\mathrm{a}, \mathrm{c}}$ & $0.09^{\mathrm{c}}$ & $-0.07^{\mathrm{a}}$ \\
\hline iNS T & 0.89 & $0.91^{\mathrm{a}}$ & $0.50^{\mathrm{b}}$ & $0.89^{\mathrm{a}}$ & $0.35^{\mathrm{b}}$ & $0.64^{\mathrm{c}}$ & $0.89^{\mathrm{a}}$ & $0.34^{\mathrm{b}}$ & $0.65^{\mathrm{c}}$ & $0.08^{\mathrm{d}}$ & $0.81^{\mathrm{a}}$ & $0.27^{\mathrm{b}}$ & $0.57^{\mathrm{c}}$ & $0.24^{\mathrm{b}}$ & $0.82^{\mathrm{a}}$ \\
\hline Auth & 0.55 & $0.69^{\mathrm{a}}$ & $0.08^{\mathrm{b}}$ & $0.75^{\mathrm{a}}$ & $0.04^{\mathrm{b}}$ & $0.22^{\mathrm{c}}$ & $0.75^{\mathrm{a}}$ & $0.03^{\mathrm{b}}$ & $0.23^{\mathrm{c}}$ & $0.00^{\mathrm{b}}$ & $0.60^{\mathrm{a}}$ & $-0.04^{b}$ & $0.14^{\mathrm{c}}$ & $0.21^{\mathrm{c}}$ & $0.78^{\mathrm{d}}$ \\
\hline iciency & 0.26 & 0.24 & 0.18 & 0.23 & 0.14 & 0.21 & $0.24^{\mathrm{a}}$ & $0.11^{\mathrm{b}}$ & $0.16^{\mathrm{a}, \mathrm{b}}$ & $\underline{0.72^{\mathrm{c}}}$ & $0.26^{\mathrm{a}}$ & $0.08^{\mathrm{b}}$ & $0.15^{\mathrm{b}}$ & $\underline{0.81^{\mathrm{c}}}$ & $0.10^{\mathrm{b}}$ \\
\hline Sup & .75 & $\underline{0.81^{\mathrm{a}}}$ & $0.34^{\mathrm{b}}$ & $0.77^{\mathrm{a}}$ & $0.17^{\mathrm{b}}$ & $0.58^{\mathrm{c}}$ & $\underline{0.77^{\mathrm{a}}}$ & $0.15^{\mathrm{b}}$ & $0.58^{\mathrm{c}}$ & $0.15^{\mathrm{b}}$ & $0.77^{\mathrm{a}}$ & $0.10^{\mathrm{b}}$ & $0.50^{\mathrm{c}}$ & $0.19^{\mathrm{b}}$ & $0.58^{\mathrm{c}}$ \\
\hline & 35 & $0.37^{\mathrm{a}}$ & $0.17^{\mathrm{b}}$ & $0.43^{\mathrm{a}}$ & $0.19^{\mathrm{b}}$ & $0.11^{\mathrm{b}}$ & $0.43^{\mathrm{a}}$ & $0.19^{\mathrm{b}}$ & $0.13^{\mathrm{b}}$ & $-0.05^{\mathrm{c}}$ & $0.38^{\mathrm{a}}$ & $0.16^{\mathrm{b}}$ & $0.07^{\mathrm{b}}$ & $0.03^{\mathrm{b}}$ & $0.40^{\mathrm{a}}$ \\
\hline & 72 & $0.68^{\mathrm{a}}$ & $0.50^{\mathrm{b}}$ & $0.66^{\mathrm{a}}$ & $0.40^{\mathrm{b}}$ & $0.53^{\mathrm{c}}$ & $0.66^{\mathrm{a}}$ & $0.41^{\mathrm{b}}$ & $0.57^{\mathrm{c}}$ & $-0.33^{\mathrm{d}}$ & $0.51^{\mathrm{a}}$ & $0.35^{\mathrm{b}}$ & $0.53^{\mathrm{a}}$ & $-0.13^{\mathrm{c}}$ & $\underline{0.81^{\mathrm{d}}}$ \\
\hline Entit & .84 & $0.81^{\mathrm{a}}$ & $0.55^{\mathrm{b}}$ & $0.75^{\mathrm{a}}$ & $0.37^{\mathrm{b}}$ & $0.70^{\mathrm{a}}$ & $0.75^{\mathrm{a}}$ & $0.35^{\mathrm{b}}$ & $0.71^{\mathrm{a}}$ & $0.11^{\mathrm{c}}$ & $\underline{0.83^{\mathrm{a}}}$ & $0.32^{\mathrm{b}}$ & $0.63^{\mathrm{c}}$ & $0.06^{\mathrm{d}}$ & $0.47^{\mathrm{e}}$ \\
\hline Explo & $\overline{0}$ & 0.60 & 0.58 & $0.48^{\mathrm{a}}$ & $0.37^{\mathrm{b}}$ & $0.76^{\mathrm{c}}$ & $0.47^{\mathrm{a}}$ & $0.36^{\mathrm{b}}$ & $0.77^{\mathrm{c}}$ & $-0.08^{\mathrm{d}}$ & $0.43^{\mathrm{a}, \mathrm{d}}$ & $0.32^{\mathrm{a}}$ & $0.77^{\mathrm{b}}$ & $0.02^{\mathrm{c}}$ & $0.50^{\mathrm{d}}$ \\
\hline HSNS & 0 & $0.26^{\mathrm{a}}$ & $0.85^{\mathrm{b}}$ & $0.22^{\mathrm{a}}$ & $0.80^{\mathrm{b}}$ & $0.58^{\mathrm{c}}$ & $0.22^{\mathrm{a}}$ & $0.78^{\mathrm{b}}$ & $\overline{0.57^{\mathrm{c}}}$ & $0.30^{\mathrm{a}}$ & $0.30^{\mathrm{a}}$ & $0.78^{\mathrm{b}}$ & $\overline{0.57^{\mathrm{c}}}$ & $0.29^{\mathrm{a}}$ & $0.11^{\mathrm{d}}$ \\
\hline NARQ & .93 & $0.87^{\mathrm{a}}$ & $0.65^{\mathrm{b}}$ & $0.82^{\mathrm{a}}$ & $0.47^{\mathrm{b}}$ & $0.78^{\mathrm{a}}$ & $0.81^{\mathrm{a}}$ & $0.45^{\mathrm{b}}$ & $0.79^{\mathrm{a}}$ & $0.07^{\mathrm{c}}$ & $0.84^{\mathrm{a}}$ & $0.41^{\mathrm{b}}$ & $0.72^{\mathrm{c}}$ & $0.10^{\mathrm{d}}$ & $0.63^{\mathrm{e}}$ \\
\hline Admiration & .83 & $\underline{0.92^{\mathrm{a}}}$ & $0.33^{\mathrm{b}}$ & $\underline{0.94^{\mathrm{a}}}$ & $0.22^{\mathrm{b}}$ & $0.49^{\mathrm{c}}$ & $\underline{0.93^{\mathrm{a}}}$ & $0.21^{\mathrm{b}}$ & $0.51^{\mathrm{c}}$ & $0.02^{\mathrm{d}}$ & $\underline{0.91^{\mathrm{a}}}$ & $0.15^{\mathrm{b}}$ & $0.40^{\mathrm{c}}$ & $0.08^{\mathrm{b}}$ & $0.74^{\mathrm{e}}$ \\
\hline Rivalry & .71 & $\overline{0.52^{\mathrm{a}}}$ & $0.78^{b}$ & $\overline{0.40^{\mathrm{a}}}$ & $0.58^{\mathrm{b}}$ & $\underline{0.82^{c}}$ & $\overline{0.39^{\mathrm{a}}}$ & $0.56^{\mathrm{b}}$ & $\underline{0.83^{\mathrm{c}}}$ & $0.10^{\mathrm{d}}$ & $\overline{0.46^{\mathrm{a}}}$ & $0.55^{\mathrm{a}}$ & $0.82^{b}$ & $0.08^{\mathrm{c}}$ & $0.28^{\mathrm{d}}$ \\
\hline NGS & & & $0.30^{\mathrm{b}}$ & $0.91^{\mathrm{a}}$ & $0.13^{\mathrm{b}}$ & $\overline{0.58^{\mathrm{c}}}$ & $0.90^{\mathrm{a}}$ & $0.11^{\mathrm{b}}$ & $\overline{0.58^{\mathrm{c}}}$ & $0.13^{\mathrm{b}}$ & $0.91^{\mathrm{a}}$ & $0.06^{\mathrm{b}}$ & $\overline{0.48^{\mathrm{c}}}$ & $0.16^{\mathrm{b}}$ & $0.67^{\mathrm{d}}$ \\
\hline & & $0.95^{\mathrm{a}}$ & $0.38^{\mathrm{b}}$ & $0.97^{\mathrm{a}}$ & $0.26^{\mathrm{b}}$ & $0.53^{\mathrm{c}}$ & $0.97^{\mathrm{a}}$ & $0.25^{\mathrm{b}}$ & $0.55^{\mathrm{c}}$ & $0.05^{\mathrm{d}}$ & $0.89^{\mathrm{a}}$ & $0.17^{\mathrm{b}}$ & $0.44^{\mathrm{c}}$ & $0.19^{\mathrm{b}}$ & $0.86^{\mathrm{d}}$ \\
\hline $\mathrm{G} / \mathrm{H}$ & .7. & $0.79^{\mathrm{a}}$ & $0.44^{\mathrm{b}}$ & $0.79^{a}$ & $0.34^{\mathrm{b}}$ & $0.52^{\mathrm{c}}$ & $0.79^{\mathrm{a}}$ & $0.35^{\mathrm{b}}$ & $0.55^{\mathrm{c}}$ & $-0.26^{\mathrm{d}}$ & $0.71^{\mathrm{a}}$ & $0.29^{\mathrm{b}}$ & $0.47^{\mathrm{c}}$ & $-0.14^{\mathrm{d}}$ & $0.77^{\mathrm{e}}$ \\
\hline L/A & .73 & $\underline{0.86}^{\mathrm{a}}$ & $0.21^{\mathrm{b}}$ & $\underline{0.90^{a}}$ & $0.12^{\mathrm{b}}$ & $0.38^{\mathrm{c}}$ & $\underline{0.90^{a}}$ & $0.11^{\mathrm{b}}$ & $0.38^{\mathrm{c}}$ & $0.07^{\mathrm{b}}$ & $\underline{0.80^{\mathrm{a}}}$ & $0.04^{\mathrm{b}}$ & $0.28^{\mathrm{c}}$ & $0.23^{\mathrm{c}}$ & $\underline{0.82^{\mathrm{a}}}$ \\
\hline $\mathrm{E} / \mathrm{E}$ & .83 & $0.79^{\mathrm{a}}$ & $0.56^{\mathrm{b}}$ & $0.76^{\mathrm{a}}$ & $0.43^{\mathrm{b}}$ & $0.64^{\mathrm{c}}$ & $0.76^{\mathrm{a}}$ & $0.41^{\mathrm{b}}$ & $0.65^{\mathrm{c}}$ & $0.11^{\mathrm{d}}$ & $0.75^{\mathrm{a}}$ & $0.36^{\mathrm{b}}$ & $0.58^{\mathrm{c}}$ & $0.18^{\mathrm{d}}$ & $0.62^{\mathrm{c}}$ \\
\hline PDQ-4+ NPD & .87 & 0.75 & 0.74 & $0.68^{\mathrm{a}}$ & $0.56^{\mathrm{b}}$ & $0.80^{\mathrm{c}}$ & $0.67^{\mathrm{a}}$ & $0.54^{\mathrm{b}}$ & $0.81^{\mathrm{c}}$ & $0.10^{\mathrm{d}}$ & $0.71^{\mathrm{a}}$ & $0.51^{\mathrm{b}}$ & $0.76^{\mathrm{a}}$ & $0.12^{\mathrm{c}}$ & $0.52^{\mathrm{b}}$ \\
\hline PES & 82 & $0.80^{\mathrm{a}}$ & $0.53^{\mathrm{b}}$ & $0.75^{\mathrm{a}}$ & $0.36^{\mathrm{b}}$ & $0.67^{\mathrm{c}}$ & $0.74^{\mathrm{a}}$ & $0.35^{\mathrm{b}}$ & $0.67^{\mathrm{c}}$ & $0.16^{\mathrm{d}}$ & $0.85^{\mathrm{a}}$ & $0.32^{\mathrm{b}}$ & $0.59^{\mathrm{c}}$ & $0.08^{\mathrm{d}}$ & $0.43^{\mathrm{b}}$ \\
\hline PID-5 & & $0.89^{\mathrm{a}}$ & $0.60^{\mathrm{b}}$ & $0.85^{\mathrm{a}}$ & $0.44^{\mathrm{b}}$ & $0.72^{\mathrm{c}}$ & $0.85^{\mathrm{a}}$ & $0.43^{\mathrm{b}}$ & $0.75^{\mathrm{c}}$ & $-0.12^{\mathrm{d}}$ & $0.80^{\mathrm{a}}$ & $0.38^{\mathrm{b}}$ & $0.67^{\mathrm{c}}$ & $-0.03^{\mathrm{d}}$ & $0.76^{\mathrm{a}}$ \\
\hline & & $0.70^{\mathrm{a}}$ & $0.56^{\mathrm{b}}$ & $0.72^{\mathrm{a}}$ & $0.48^{\mathrm{b}}$ & $0.51^{\mathrm{b}}$ & $0.72^{\mathrm{a}}$ & $0.49^{b}$ & $0.55^{\mathrm{b}}$ & $\underline{-0.33^{d}}$ & $0.59^{\mathrm{a}}$ & $0.44^{\mathrm{b}}$ & $0.49^{\mathrm{b}}$ & $-0.16^{\mathrm{c}}$ & $\underline{0.81^{d}}$ \\
\hline & 85 & ${\underline{0.86^{\mathrm{a}}}}$ & $0.49^{\mathrm{b}}$ & $\underline{0.77^{\mathrm{a}}}$ & $0.27^{\mathrm{b}}$ & $\underline{0.77^{\mathrm{a}}}$ & $0.76^{\mathrm{a}}$ & $0.25^{\mathrm{b}}$ & $0.77^{\mathrm{a}}$ & $\overline{0.14^{b}}$ & $\underline{0.83^{\mathrm{a}}}$ & $0.21^{\mathrm{b}}$ & $0.70^{\mathrm{c}}$ & $0.11^{\mathrm{b}}$ & $\overline{0.51^{\mathrm{d}}}$ \\
\hline PNI 1 & 0 & $0.50^{\mathrm{a}}$ & $0.92^{\mathrm{b}}$ & $0.53^{\mathrm{a}}$ & $0.92^{\mathrm{b}}$ & $0.55^{\mathrm{a}}$ & $0.53^{\mathrm{a}}$ & $0.91^{\mathrm{b}}$ & $0.56^{\mathrm{a}}$ & $0.15^{\mathrm{c}}$ & $0.56^{\mathrm{a}}$ & $0.89^{\mathrm{b}}$ & $0.51^{\mathrm{a}, \mathrm{d}}$ & $0.20^{\mathrm{c}}$ & $0.42^{\mathrm{d}}$ \\
\hline PNI Gr & .75 & 0.67 & 0.59 & $0.74^{\mathrm{a}}$ & $0.60^{\mathrm{b}}$ & $0.38^{\mathrm{c}}$ & $0.75^{\mathrm{a}}$ & $0.60^{\mathrm{b}}$ & $0.40^{\mathrm{c}}$ & $0.08^{\mathrm{d}}$ & $0.72^{\mathrm{a}}$ & $0.55^{\mathrm{b}}$ & $0.31^{\mathrm{c}}$ & $0.17^{\mathrm{c}}$ & $0.63^{\mathrm{b}}$ \\
\hline Grand. fantasy & 0.63 & $0.49^{\mathrm{a}}$ & $0.62^{\mathrm{b}}$ & $0.55^{\mathrm{a}}$ & $0.64^{\mathrm{b}}$ & $0.35^{\mathrm{c}}$ & $0.55^{\mathrm{a}}$ & $0.64^{\mathrm{a}}$ & $0.35^{\mathrm{b}}$ & $0.16^{\mathrm{c}}$ & $0.58^{\mathrm{a}}$ & $0.61^{\mathrm{a}}$ & $0.28^{b, c}$ & $0.19^{\mathrm{b}}$ & $0.40^{\mathrm{c}}$ \\
\hline Exploitative & .66 & $0.73^{\mathrm{a}}$ & $0.28^{\mathrm{b}}$ & $0.73^{\mathrm{a}}$ & $0.16^{\mathrm{b}}$ & $0.44^{\mathrm{c}}$ & $0.72^{\mathrm{a}}$ & $0.15^{\mathrm{b}}$ & $0.45^{\mathrm{c}}$ & $0.04^{\mathrm{b}}$ & $0.62^{\mathrm{a}}$ & $0.09^{\mathrm{b}}$ & $0.38^{\mathrm{c}}$ & $0.22^{\mathrm{b}}$ & $0.73^{\mathrm{d}}$ \\
\hline & & & & 0.44 & & $0.06^{\mathrm{c}}$ & $0.45^{\mathrm{a}}$ & & $0.08^{\mathrm{b}}$ & $-0.08^{c}$ & $0.44^{\mathrm{a}}$ & & $0.00^{\mathrm{b}}$ & $-0.05^{b}$ & $0.36^{\mathrm{a}}$ \\
\hline PNI V & 0 & $0.33^{\mathrm{a}}$ & $0.95^{\mathrm{b}}$ & $0.33^{\mathrm{a}}$ & $0.94^{\mathrm{b}}$ & $0.55^{\mathrm{c}}$ & $0.33^{\mathrm{a}}$ & $0.93^{\mathrm{b}}$ & $0.55^{\mathrm{c}}$ & $0.17^{\mathrm{d}}$ & $0.39^{\mathrm{a}}$ & $0.92^{\mathrm{b}}$ & $0.53^{\mathrm{c}}$ & $0.18^{\mathrm{d}}$ & $0.24^{\mathrm{d}}$ \\
\hline & & $0.17^{\mathrm{a}}$ & ${\underline{0.85^{b}}}^{\mathrm{b}}$ & $0.20^{\mathrm{a}}$ & $\underline{0.90^{b}}$ & $0.37^{\mathrm{c}}$ & $0.20^{\mathrm{a}}$ & $\underline{0.91^{\mathrm{b}}}$ & $0.40^{\mathrm{c}}$ & $-0.12^{\mathrm{d}}$ & $0.23^{\mathrm{a}}$ & $\underline{0.91^{\mathrm{b}}}$ & $0.38^{\mathrm{c}}$ & $-0.11^{\mathrm{d}}$ & $0.20^{\mathrm{a}}$ \\
\hline Deva & 0 & $0.30^{\mathrm{a}}$ & $\underline{0.79^{b}}$ & $0.26^{\mathrm{a}}$ & $0.74^{\mathrm{b}}$ & $0.54^{\mathrm{c}}$ & $0.27^{\mathrm{a}}$ & $0.73^{\mathrm{b}}$ & $0.54^{\mathrm{c}}$ & $0.23^{\mathrm{a}}$ & $0.35^{\mathrm{a}}$ & $0.73^{\mathrm{b}}$ & $0.52^{\mathrm{c}}$ & $0.19^{\mathrm{d}}$ & $0.12^{\mathrm{d}}$ \\
\hline Entitlement rage & 0.75 & $0.51^{\mathrm{a}}$ & $\underline{0.88^{b}}$ & $0.47^{\mathrm{a}}$ & $\underline{0.79^{b}}$ & $0.68^{\mathrm{c}}$ & $0.47^{\mathrm{a}}$ & $\underline{0.78^{b}}$ & $0.69^{c}$ & $0.11^{\mathrm{d}}$ & $0.52^{\mathrm{a}}$ & $\underline{0.76^{b}}$ & $0.66^{\mathrm{c}}$ & $0.11^{\mathrm{d}}$ & $0.34^{\mathrm{e}}$ \\
\hline Hiding the self & 0.38 & $0.18^{\mathrm{a}}$ & $\overline{0.59^{\mathrm{b}}}$ & $0.20^{\mathrm{a}}$ & $\overline{0.61^{\mathrm{b}}}$ & $0.28^{\mathrm{a}}$ & $0.21^{\mathrm{a}}$ & $\overline{0.59^{\mathrm{b}}}$ & $0.26^{\mathrm{a}}$ & $\underline{0.55^{b}}$ & $0.24^{\mathrm{a}}$ & $\overline{0.58^{\mathrm{b}}}$ & $0.25^{\mathrm{a}, \mathrm{c}}$ & $\underline{0.64^{b}}$ & $0.13^{\mathrm{c}}$ \\
\hline SCID-II NPD & .92 & 0.81 & 0.76 & $0.73^{\mathrm{a}}$ & $0.56^{\mathrm{b}}$ & $0.86^{\mathrm{c}}$ & $0.72^{\mathrm{a}}$ & $0.54^{\mathrm{b}}$ & $0.87^{\mathrm{c}}$ & $\overline{0.11^{\mathrm{d}}}$ & $0.77^{\mathrm{a}}$ & $0.50^{\mathrm{b}}$ & $0.81^{\mathrm{a}}$ & $\overline{0.11^{\mathrm{c}}}$ & $0.53^{\mathrm{b}}$ \\
\hline SD3 Narcissism & 0.79 & $0.88^{\mathrm{a}}$ & $0.30^{\mathrm{b}}$ & $0.90^{\mathrm{a}}$ & $0.19^{\mathrm{b}}$ & $0.47^{\mathrm{c}}$ & $0.90^{\mathrm{a}}$ & $0.19^{\mathrm{b}}$ & $0.49^{\mathrm{c}}$ & $-0.09^{\mathrm{d}}$ & $0.82^{\mathrm{a}}$ & $0.12^{\mathrm{b}}$ & $0.39^{\mathrm{c}}$ & $0.03^{\mathrm{b}}$ & $0.81^{\mathrm{a}}$ \\
\hline
\end{tabular}

Note. All correlations greater than or equal to $|r|=.11$ are significant at $\mathrm{p}<.01$. At each factor level (i.e., F3.1, F3.2, F3.3), correlations in the same row with different superscripts are significantly different from one another at $\mathrm{p}<.01$. The five largest facet-level correlations for each factor are underlined and in bold. FFNI = Five Factor Narcissism Inventory - Short Form; Grand. = Grandiose; Ad. = Admiration; GNS = Grandiose Narcissism Scale; HSNS = Hypersensitive Narcissism Scale; NARQ = Narcissistic Admiration and Rivalry Questionnaire; NGS = Narcissistic Grandiosity Scale; NPI = Narcissistic Personality Inventory; G/E = Grandiose Exhibitionism; L/A = Leadership/Authority; E/E = Entitlement/Exploitativeness; PDQ-4+ = Personality Diagnostic Questionnaire-4 Narcissistic Personality Disorder Scale; PES = Psychological Entitlement Scale; PID-5 = Personality Inventory for the DSM-5; Atten = Attention; PNI = Pathological Narcissism Inventory; SSSE $=$ Selfsacrificing Self Enhancement; SE = Self-esteem; SCID-II = Structured Clinical Interview for DSM-IV Personality Disorders Personality Questionnaire - NPD Scale; SD3 = Short Dark Triad 


\section{STRUCTURE OF NARCISSISM}

\section{Table 2}

\section{Factor Score Correlations with Five Factor Model}

\begin{tabular}{|c|c|c|c|c|c|c|c|c|c|c|c|c|c|c|c|}
\hline & F1.1 & F2.1 & F2.2 & F3.1 & F3.2 & F3.3 & F4.1 & F4.2 & F4.3 & F4.4 & F5.1 & F5.2 & F5.3 & F5.4 & F5.5 \\
\hline Neur & 0.07 & $024^{a}$ & $0.61^{b}$ & $-0.26^{a}$ & $0.66^{b}$ & $0.19^{\mathrm{c}}$ & $-0.25^{a}$ & $0.66^{\mathrm{b}}$ & $0.19^{c}$ & $0.13^{\mathrm{c}}$ & $-0.18^{a}$ & $0.69^{b}$ & $0.23^{\mathrm{c}}$ & $0.08^{\mathrm{d}}$ & 025 \\
\hline & 0.04 & .25 & $\underline{0.52^{b}}$ & $-0.22^{\mathrm{a}}$ & $0.60^{b}$ & $0.09^{c}$ & $-0.21^{\mathrm{a}}$ & $\underline{0.60^{b}}$ & $0.09^{c}$ & $0.17^{\mathrm{c}}$ & $0.14^{\mathrm{a}}$ & $0.63^{b}$ & $0.12^{\mathrm{c}}$ & $.13^{\mathrm{c}}$ & $0.23^{\mathrm{d}}$ \\
\hline & 0.24 & $05^{\mathrm{a}}$ & $\overline{0.49^{b}}$ & $0.01^{\mathrm{a}}$ & $\overline{0.44^{b}}$ & $0.34^{\mathrm{c}}$ & $0.01^{\mathrm{a}}$ & $\overline{0.43^{b}}$ & $0.33^{\mathrm{b}, \mathrm{c}}$ & $\underline{0.21^{\mathrm{c}}}$ & $.05^{\mathrm{a}}$ & $\overline{0.44^{\mathrm{b}}}$ & $0.35^{\mathrm{b}, \mathrm{c}}$ & $0.22^{\mathrm{c}}$ & $-0.02^{\mathrm{a}}$ \\
\hline & 0.01 & $27^{\mathrm{a}}$ & $\underline{0.52^{\mathrm{b}}}$ & $-0.27^{\mathrm{a}}$ & $0.59^{b}$ & $0.10^{c}$ & $-0.27^{a}$ & $\underline{0.59^{b}}$ & $0.10^{\mathrm{c}}$ & $0.11^{\mathrm{c}}$ & $-0.22^{\mathrm{a}}$ & $\underline{0.62^{b}}$ & $0.15^{\mathrm{c}}$ & $0.09^{c}$ & $-0.22^{\mathrm{a}}$ \\
\hline & & & & & $\overline{0.50^{b}}$ & $0.04^{\mathrm{c}}$ & $-0.38^{a}$ & $\overline{0.50^{b}}$ & & $0.07^{\mathrm{c}}$ & & & $0.09^{c}$ & $-0.05^{\mathrm{c}}$ & $-0.42^{\mathrm{u}}$ \\
\hline & 13 & .0 & $0.40^{\mathrm{b}}$ & $-0.05^{\mathrm{a}}$ & $0.42^{b}$ & $0.15^{\mathrm{c}}$ & $-0.05^{\mathrm{a}}$ & $0.42^{b}$ & $0.16^{\mathrm{c}}$ & $0.04^{\mathrm{a}, \mathrm{c}}$ & $-0.03^{\mathrm{a}}$ & $0.43^{b}$ & $0.17^{\mathrm{c}}$ & $.05^{, 40}$ & $-0.03^{a}$ \\
\hline & 0.00 & $.26^{\mathrm{a}}$ & $\underline{0.47^{\mathrm{b}}}$ & $-0.29^{\mathrm{a}}$ & $\underline{0.50^{b}}$ & $0.15^{\mathrm{c}}$ & $-0.29^{\mathrm{a}}$ & $\underline{0.50^{b}}$ & $0.16^{\mathrm{c}}$ & $-0.03^{\mathrm{d}}$ & $-0.21^{\mathrm{a}, \mathrm{d}}$ & $\underline{0.54^{\mathrm{b}}}$ & $0.21^{\mathrm{c}}$ & $-0.10^{\mathrm{a}}$ & $-0.26^{\mathrm{d}}$ \\
\hline $\mathrm{xtr}$ & 0.34 & & $-0.17^{b}$ & $0.63^{\mathrm{a}}$ & $-\overline{-0.17^{b}}$ & $-0.02^{c}$ & $0.63^{\mathrm{a}}$ & $\overline{-0.16^{b}}$ & $0.01^{\mathrm{c}}$ & $-0.25^{b}$ & $0.48^{\mathrm{a}}$ & $\overline{-0.22^{b}}$ & $-0.08^{\mathrm{c}}$ & $-0.08^{b, c}$ & $0.69^{d}$ \\
\hline & & & & 0.4 & $-0.21^{b}$ & $-0.15^{b}$ & $0.41^{\mathrm{a}}$ & $-0.20^{\mathrm{b}}$ & $-0.12^{b}$ & $\underline{-0.36^{c}}$ & & $-0.24^{b}$ & $-0.19^{b}$ & $-0.24^{b}$ & $\underline{0.50^{c}}$ \\
\hline & 0.2 & $\underline{0.41^{\mathrm{a}}}$ & & $0.44^{\mathrm{a}}$ & $-0.07^{b}$ & $0.07^{\mathrm{c}}$ & $\underline{0.44^{\mathrm{a}}}$ & $-0.06^{\mathrm{b}}$ & $0.10^{c}$ & $-0.35^{d}$ & $0.33^{\mathrm{a}}$ & $-0.10^{\mathrm{b}}$ & $0.05^{\mathrm{c}}$ & $-0.24^{b}$ & $\overline{0.52^{\mathrm{d}}}$ \\
\hline & $\underline{0.35}$ & $0.54^{\mathrm{a}}$ & & $0.60^{\mathrm{a}}$ & $-0.15^{b}$ & $0.04^{\mathrm{c}}$ & $\underline{0.60^{\mathrm{a}}}$ & $-0.15^{b}$ & $0.06^{\mathrm{c}}$ & $-0.07^{b, c}$ & $\underline{0.45^{\mathrm{a}}}$ & $-0.21^{b}$ & $-0.02^{\mathrm{c}}$ & $0.13^{\mathrm{c}}$ & $\underline{0.67^{d}}$ \\
\hline & 0.18 & $33^{\mathrm{a}}$ & -0.1 & $\overline{0.38^{\mathrm{a}}}$ & $-0.15^{b}$ & $-0.04^{b}$ & $0.38^{\mathrm{a}}$ & $-0.15^{b}$ & $-0.04^{b, c}$ & $0.05^{\mathrm{c}}$ & $0.31^{a}$ & $-0.19^{b}$ & $-0.10^{\mathrm{b}}$ & $5^{c}$ & $.37^{a}$ \\
\hline & $\underline{0.36}$ & $.40^{\mathrm{a}}$ & $0.13^{b}$ & $0.44^{\mathrm{a}}$ & $0.10^{\mathrm{b}}$ & $0.16^{\mathrm{b}}$ & $\underline{0.44^{\mathrm{a}}}$ & $0.10^{\mathrm{b}}$ & $0.17^{b}$ & $-0.07^{c}$ & $\underline{0.37^{\mathrm{a}}}$ & $0.07^{\mathrm{b}}$ & $0.12^{b}$ & $0.02^{b}$ & $0.44^{\mathrm{a}}$ \\
\hline & 0.12 & $0.32^{\mathrm{a}}$ & -0.2 & $0.40^{\mathrm{a}}$ & $-0.24^{b}$ & $-0.18^{b}$ & $0.41^{\mathrm{a}}$ & $-0.23^{b}$ & $-0.16^{b}$ & $\underline{-0.20^{b}}$ & $0.31^{\mathrm{a}}$ & $-0.27^{b}$ & $-0.23^{b, c}$ & & $0.41^{\mathrm{d}}$ \\
\hline & & & & $12^{\mathrm{a}}$ & $0.09 \mathrm{a}$ & -0.1 & $0.12^{\mathrm{a}}$ & $0.10^{\mathrm{a}}$ & -0.1 & $-\overline{-0.01^{\mathrm{a}, \mathrm{b}}}$ & & $0.08^{\mathrm{a}}$ & & & \\
\hline & & 10 & 0.18 & $0.17^{\mathrm{a}}$ & $0.25^{\mathrm{a}}$ & $-0.02^{b}$ & $\mathrm{a}, \mathrm{c}$ & $0.25^{\mathrm{a}}$ & -0.0 & $0.07^{\mathrm{c}}$ & $14^{\mathrm{a}}$ & $0.24^{\mathrm{a}}$ & & $.13^{\mathrm{a}}$ & $0.17^{\mathrm{a}}$ \\
\hline & .04 & $01^{\mathrm{a}}$ & -0.1 & $0.09^{\mathrm{a}}$ & $-0.01^{\mathrm{a}}$ & & & $0.00^{\mathrm{a}}$ & -0.2 & $-0.01^{\mathrm{a}}$ & $0.08^{\mathrm{a}}$ & $-0.02^{a}$ & $-0.26^{b}$ & $02^{\mathrm{a}}$ & $0.09^{\mathrm{a}}$ \\
\hline & & 1 & $0.24^{b}$ & -0.0 & $0.38^{b}$ & & -0.0 & $0.39^{b}$ & & $-0.10^{\mathrm{a}}$ & $-0.08^{a}$ & $0.40^{b}$ & & & $-0.02^{\mathrm{a}}$ \\
\hline & & & & 0.1 & -0.2 & & 0.1 & -0.2 & -0.0 & $-0.11^{b, c}$ & $0.11^{\mathrm{a}}$ & -0.2 & -0.0 & $-0.04^{\mathrm{c}}$ & $0.22^{\mathrm{d}}$ \\
\hline & & & & $13^{\mathrm{a}}$ & -0.0 & & & -0.0 & -0.1 & $0.07^{\mathrm{c}}$ & $0.08^{\mathrm{a}}$ & -0.1 & -0 . & & \\
\hline & & & 0.06 & & 0.04 & $0.06^{\mathrm{b}}$ & $-0.05^{\mathrm{a}}$ & $0.03^{\mathrm{a}, \mathrm{b}}$ & & $0.04^{\mathrm{a}, \mathrm{b}}$ & 0.03 & 0.04 & $0.07^{\mathrm{a}}$ & 0.01 & $-0.07^{b}$ \\
\hline gr & .59 & & -0.50 & & -0.2 & $-0.78^{b}$ & $-0.34^{\mathrm{a}}$ & $-0.22^{b}$ & $-0.77^{\mathrm{c}}$ & $-0.21^{\mathrm{a}, \mathrm{b}}$ & $-0.37^{a}$ & $-0.20^{b}$ & $-0.78^{c}$ & $-0.24^{b}$ & $-0.27^{b}$ \\
\hline & & & & 0.0 & -0.1 & $-0.29^{b}$ & $0.05^{\mathrm{a}}$ & $-0.17^{b}$ & $-0.26^{b}$ & $\underline{-0.49^{c}}$ & $-0.01^{\mathrm{a}}$ & $-0.17^{b}$ & $-0.29^{b}$ & $-0.50^{c}$ & $0.12^{\mathrm{d}}$ \\
\hline & & & $\underline{-0}$. & $-0.45^{\mathrm{a}}$ & & -0.6 & $-0.44^{\mathrm{a}}$ & -0.3 & $-0.65^{b}$ & $0.08^{\mathrm{c}}$ & $-0.39^{a, d}$ & $-0.32^{\mathrm{a}}$ & $-0.64^{b}$ & $\overline{-0.01^{c}}$ & $-0.47^{\mathrm{d}}$ \\
\hline & & & & & -0 . & & & $-0.09^{b}$ & $\overline{-0.54^{\mathrm{c}}}$ & $-0.15^{b}$ & & $-0.12^{b}$ & $\overline{-0.60^{c}}$ & & $\overline{0.18}$ \\
\hline & .49 & & & & & $-0.57^{b}$ & $-0.29^{a}$ & $-0.30^{\mathrm{a}}$ & $-0.57^{b}$ & $-0.13^{c}$ & $-0.29^{a}$ & $-0.28^{a}$ & $-0.57^{b}$ & $-0.18^{a}$ & -0.27 \\
\hline & .62 & $73^{2}$ & 01 & $-0.6^{a}$ & $-0.02^{b}$ & $\overline{-0.48^{c}}$ & $-0.69^{a}$ & $-0.01^{b}$ & $\overline{-0.50^{c}}$ & $0.12^{b}$ & $-0.65^{a}$ & $0.04^{b}$ & $\overline{-0.43^{c}}$ & $0.07^{b}$ & $\underline{-0.59}$ \\
\hline & & & & $\overline{-0.0}$ & & $-0.51^{b}$ & $\overline{-0.07^{a}}$ & $0.06^{\mathrm{b}}$ & $-0.50^{c}$ & $-0.14^{\mathrm{a}}$ & $\overline{-0.12^{a}}$ & $0.06^{\mathrm{b}, \mathrm{d}}$ & $-0.53^{c}$ & & $\overline{-0.01^{\circ}}$ \\
\hline & & & & & -0.4 & & & $-0.42^{b}$ & $-0.36^{b}$ & & & & & & $0.14^{\mathrm{a}}$ \\
\hline & & & & $9^{\mathrm{a}}$ & $-0.27^{b}$ & & & $-0.28^{b}$ & $-0.16^{\mathrm{c}}$ & $.14^{\mathrm{d}}$ & & $-0.32^{b}$ & $-0.23^{b}$ & $\underline{0.23^{\mathrm{a}}}$ & $0.34^{\mathrm{a}}$ \\
\hline & & & & $0.06^{\mathrm{a}}$ & $-0.18^{b}$ & $-0.20^{b}$ & $0.07^{\mathrm{a}}$ & $-0.17^{b}$ & $-0.21^{b}$ & $0.03^{\mathrm{a}}$ & $4^{\mathrm{a}}$ & $-0.19^{b}$ & $-0.23^{b}$ & $0.06^{\mathrm{a}}$ & $0.06^{\mathrm{a}}$ \\
\hline & .34 & 1 & & $-0.07^{a}$ & $-0.33^{b}$ & $-0.53^{c}$ & $-0.06^{a}$ & $-0.32^{b}$ & $-0.54^{\mathrm{c}}$ & $0.09^{d}$ & $-0.09^{a}$ & $-0.33^{b}$ & $\underline{-0.57^{c}}$ & $0.11^{\mathrm{d}}$ & -0.08 \\
\hline & & & & & -0.1 & & & -0.1 & -0 . & & 0.3 & -0. & $\overline{-0.22^{b}}$ & $\underline{0.24^{\mathrm{a}}}$ & $0.34^{\mathrm{a}}$ \\
\hline & & & & & -0.44 & $-0.22^{c}$ & $0.13^{\mathrm{a}}$ & $\underline{-0.44^{b}}$ & $-0.22^{\mathrm{c}}$ & $0.00^{\mathrm{a}}$ & $\overline{0.07^{\mathrm{a}}}$ & & $-0.25^{\mathrm{c}}$ & $\overline{0.04^{\mathrm{a}}}$ & $0.13^{\mathrm{a}}$ \\
\hline Cauti & .29 & 1 & -0.44 & $-0.11^{\mathrm{a}}$ & $-0.41^{b}$ & $-0.30^{c}$ & $-0.11^{\mathrm{a}}$ & $-0.40^{\mathrm{b}}$ & $-0.31^{b}$ & $-0.02^{\mathrm{a}}$ & $-0.13^{a}$ & $-0.40^{\mathrm{b}}$ & $-0.31^{b}$ & $-0.03^{a}$ & -0.11 \\
\hline
\end{tabular}

Note. All correlations greater than or equal to $|r|=.11$ are significant at $\mathrm{p}<.01$. At each factor level (i.e., F3.1, F3.2, F3.3), correlations in the same row with different superscripts are significantly different from one another at $\mathrm{p}<.01$. The five largest facet-level correlations for each factor are underlined and in bold. Con. $=$ Consciousness; Excite $=$ Excitement; Achieve Strive $=$ Achievement Striving 


\section{STRUCTURE OF NARCISSISM}

\section{Table 3}

Factor Score Correlations with Narcissism Scales

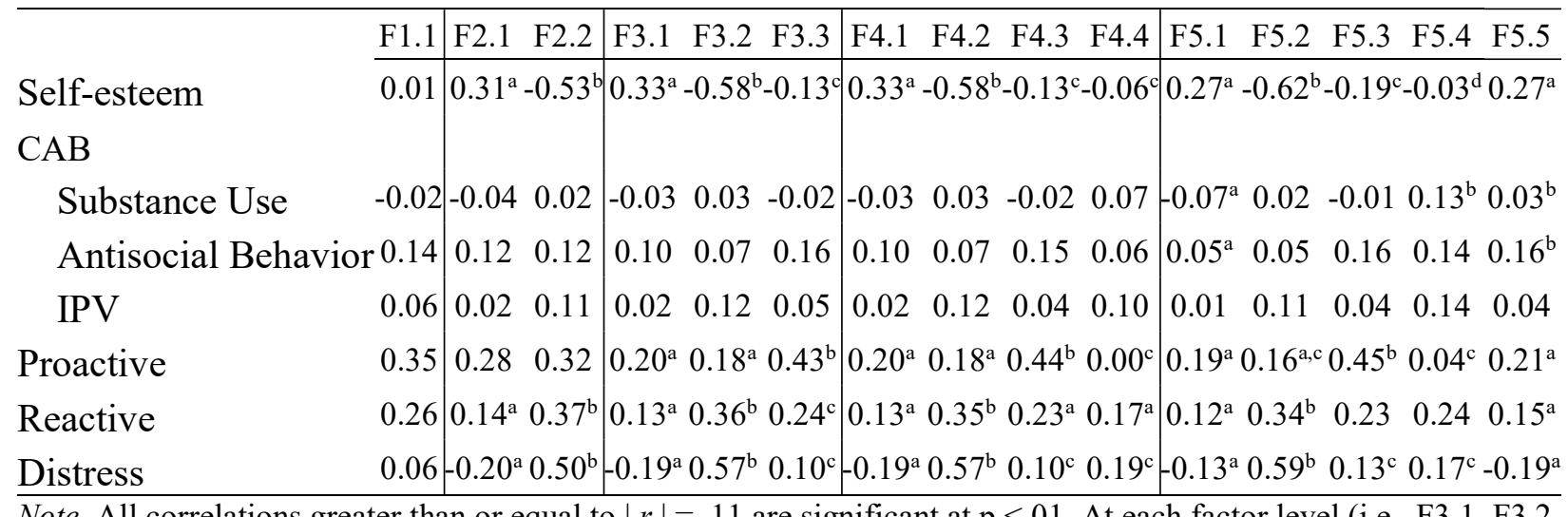

Note. All correlations greater than or equal to $|r|=.11$ are significant at $\mathrm{p}<.01$. At each factor level (i.e., F3.1, F3.2, F3.3), correlations in the same row with different superscripts are significantly different from one another at $\mathrm{p}<.01$.

The five largest facet-level correlations for each factor are underlined and in bold. CAB = Crime and Analogous Behavior Scale; IPV = Intimate Partner Violence; Proactive $=$ Proactive Aggression; Reactive $=$ Reactive Aggression; Distress $=$ Emotional Distress 
STRUCTURE OF NARCISSISM

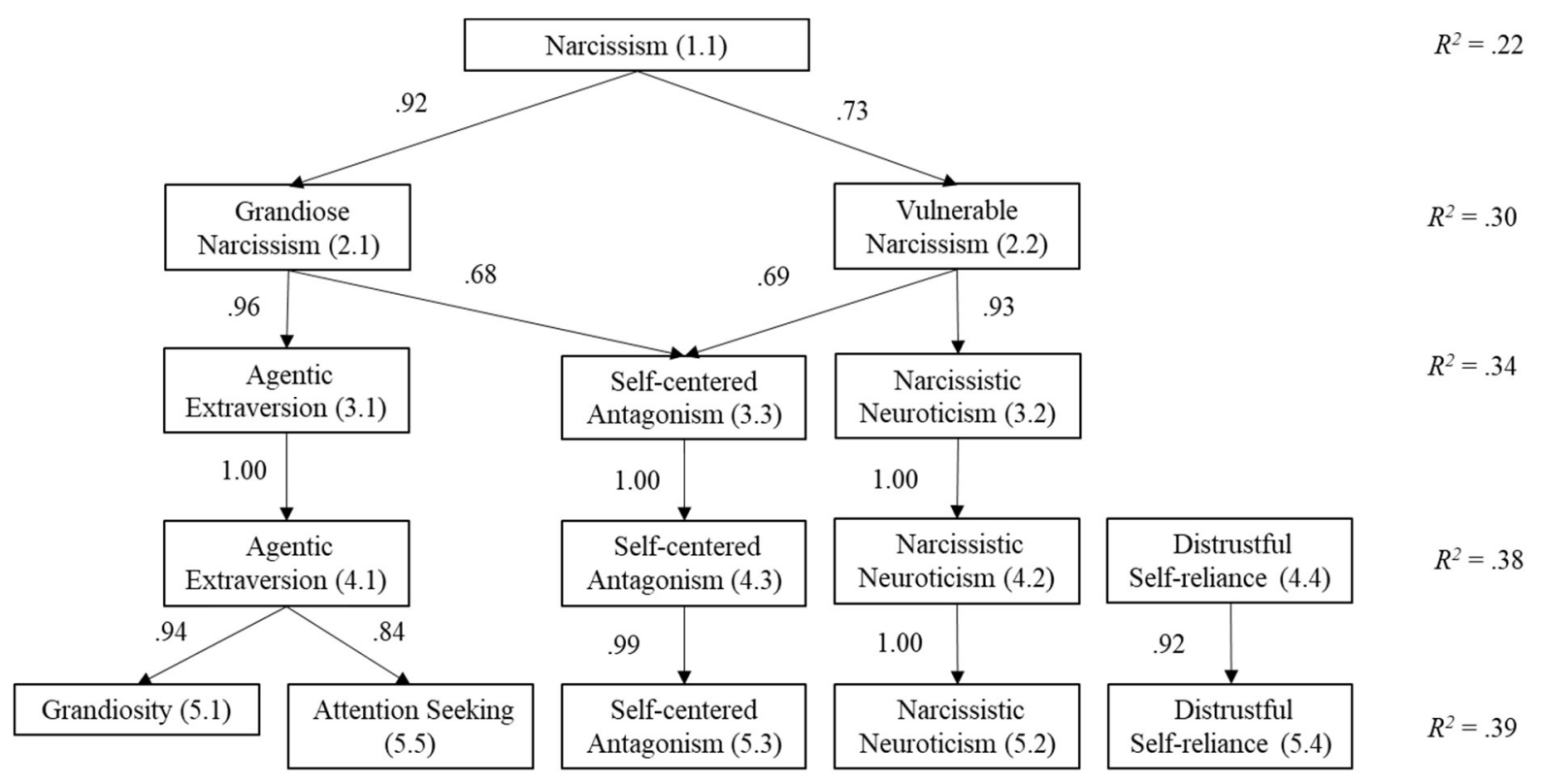

Figure 1. Hierarchical Structure of Narcissism

Note. Only correlations going from one level of the hierarchy to the next are depicted. Correlations less than .65 were removed. 